\title{
Organic particulate matter formation at varying relative humidity using surrogate secondary and primary organic compounds with activity corrections in the condensed phase obtained using a method based on the Wilson equation
}

\author{
E. I. Chang ${ }^{1}$ and J. F. Pankow ${ }^{2}$ \\ ${ }^{1}$ Bonneville Power Administration, P.O. Box 3621, Portland, OR 97208-3621, USA \\ ${ }^{2}$ Department of Chemistry and Department of Civil and Environmental Engineering, Portland State University, P.O. Box 751, \\ Portland, OR 97207-0751, USA
}

Received: 23 October 2007 - Published in Atmos. Chem. Phys. Discuss.: 22 January 2008

Revised: 28 October 2009 - Accepted: 24 February 2010 - Published: 21 June 2010

\begin{abstract}
Secondary organic aerosol (SOA) formation in the atmosphere is currently often modeled using a multiple lumped "two-product" $(N \cdot 2 \mathrm{p})$ approach. The $N \cdot 2 \mathrm{p}$ approach neglects: 1$)$ variation of activity coefficient $\left(\zeta_{i}\right)$ values and mean molecular weight $\overline{\mathrm{MW}}$ in the particulate matter (PM) phase; 2) water uptake into the PM; and 3) the possibility of phase separation in the PM. This study considers these effects by adopting an $(N \cdot 2 \mathrm{p})^{\zeta_{p} \overline{\mathrm{MW}}, \theta}$ approach $(\theta$ is a phase index). Specific chemical structures are assigned to 25 lumped SOA compounds and to 15 representative primary organic aerosol (POA) compounds to allow calculation of $\zeta_{i}$ and $\overline{\mathrm{MW}}$ values. The SOA structure assignments are based on chamber-derived $2 p$ gas/particle partition coefficient values coupled with known effects of structure on vapor pressure $p_{\mathrm{L}, i}^{\mathrm{o}}(\mathrm{atm})$. To facilitate adoption of the $(N \cdot 2 \mathrm{p})^{\zeta_{p} \overline{\mathrm{MW}}, \theta}$ approach in large-scale models, this study also develops CP-Wilson.1 (Chang-Pankow-Wilson.1), a group-contribution $\zeta_{i}$-prediction method that is more computationally economical than the UNIFAC model of Fredenslund et al. (1975). Group parameter values required by CP-Wilson. 1 are obtained by fitting $\zeta_{i}$ values to predictions from UNIFAC. The $(N \cdot 2 \mathrm{p})^{\zeta_{p} \overline{\mathrm{MW}}, \theta}$ approach is applied (using CP-Wilson.1) to several real $\alpha$-pinene $/ \mathrm{O}_{3}$ chamber cases for high reacted hydrocarbon levels $(\triangle \mathrm{HC} \approx 400$ to $1000 \mu \mathrm{g} \mathrm{m}^{-3}$ ) when relative humidity $(\mathrm{RH}) \approx 50 \%$. Good agreement between the chamber and predicted results is ob-
\end{abstract}

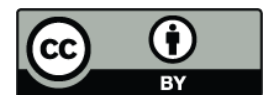

Correspondence to: J. F. Pankow (pankowj@pdx.edu) tained using both the $(N \cdot 2 \mathrm{p})^{\zeta_{p} \overline{\mathrm{MW}}, \theta}$ and $N \cdot 2 \mathrm{p}$ approaches, indicating relatively small water effects under these conditions. However, for a hypothetical $\alpha$-pinene $/ \mathrm{O}_{3}$ case at $\Delta \mathrm{HC}=30 \mu \mathrm{g} \mathrm{m}^{-3}$ and $\mathrm{RH}=50 \%$, the $(N \cdot 2 \mathrm{p})^{\zeta_{p} \overline{\mathrm{MW}}, \theta}$ approach predicts that water uptake will lead to an organic PM level that is more double that predicted by the $N \cdot 2 \mathrm{p}$ approach. Adoption of the $(N \cdot 2 \mathrm{p})^{\zeta p} \overline{\mathrm{MW}}, \theta$ approach using reasonable lumped structures for SOA and POA compounds is recommended for ambient PM modeling.

\section{Introduction}

A significant fraction of the fine particulate matter $(\mathrm{PM})$ in the atmosphere can be organic in nature, and so that fraction is of interest for visibility, health effect, and climate effect reasons (Mazurek et al., 1997; Pope, 2000; Bates et al., 2006). Organic PM (OPM) is always a complex mixture, and usually contains compounds loosely categorized as primary organic aerosol (POA) compounds and secondary organic aerosol (SOA) compounds. OPM can also contain compounds that have been formed by a variety of accretion reactions in which reactive SOA and POA compounds combine to yield products of appreciable molecular weight and low vapor pressure (Kalberer et al., 2004; Barsanti and Pankow, 2004, 2005, 2006).

Absorptive gas/particle (G/P) partitioning may be parameterized according to the model of Pankow (1994a). In the case of one absorbing phase within the PM, for compound $i$

Published by Copernicus Publications on behalf of the European Geosciences Union. 
the equilibrium partitioning constant $K_{\mathrm{p}, i}\left(\mathrm{~m}^{3} \mu \mathrm{g}^{-1}\right)$ is given by

$$
K_{\mathrm{p}, i}=\frac{c_{\mathrm{p}, i}}{c_{\mathrm{g}, i}}=\frac{R T f}{10^{6} \overline{\mathrm{MW}} \zeta_{i} p_{\mathrm{L}, i}^{\mathrm{o}}}
$$

where: $\quad c_{\mathrm{p}, i} \quad\left(\mathrm{ng}_{\mu} \mathrm{g}^{-1}\right)=\mathrm{P}$-phase concentration; $\quad c_{\mathrm{g}, i}$ $\left(\mathrm{ng} \mathrm{m}^{-3}\right)=\mathrm{G}$-phase concentration; $R$ is the gas constant $\left(=8.2 \times 10^{-5} \mathrm{~m}^{3} \mathrm{~atm} \mathrm{~mol}^{-1} \mathrm{~K}^{-1}\right) ; T(\mathrm{~K})=$ temperature; $f$ is the weight fraction of the PM that is the absorbing phase (often taken to be unity for OPM calculations); $\overline{\mathrm{MW}}\left(\mathrm{g} \mathrm{mol}^{-1}\right)=$ mean molecular weight of the absorbing phase; $p_{\mathrm{L}, i}^{\mathrm{o}}(\mathrm{atm})=$ vapor pressure of $i$; and $\zeta_{i}=$ molefraction-based activity coefficient of $i . K_{p, i}$ values generally depend strongly on $T$ because $p_{\mathrm{L}, i}^{\mathrm{o}}$ is usually a strong function of $T$. Significant temporal and spatial variations in $K_{\mathrm{p}, i}$ values can also be caused by variations in $\zeta_{i}$ and $\overline{\mathrm{MW}}$ due to changes in the types and levels of the compounds (including water) in the P-phase mixture.

Many of the applications of the Pankow (1994a, b) model for predicting secondary OPM formation in the atmosphere have been based on the "two-product" simplification of Odum et al. (1996). This implementation acknowledges that a parent hydrocarbon (HC, e.g. toluene, $\alpha$-pinene, etc.) will be oxidized to a range of secondary products, but assumes that the mix of products can be represented using up to two hypothetical "lumped" surrogate compounds. For each parent HC, yield and compound characteristics for two lumped compounds are obtained by fitting chamber yield data to four-parameters: two stoichiometric formation $\alpha_{i}$ factors and two $K_{\mathrm{p}, i}$ values. (With one lumped product, one $\alpha_{i}$ and one $K_{\mathrm{p}, i}$ value are invoked.) With $\Delta \mathrm{HC}\left(\mu \mathrm{g} \mathrm{m}^{-3}\right)$ giving the amount of reacted $\mathrm{HC}$, for each of the lumped products, the total $(\mathrm{G}+\mathrm{P})$ amount formed is assumed to be given by $T_{i}=\alpha_{i} \Delta \mathrm{HC}\left(\mu \mathrm{g} \mathrm{m}^{-3}\right)$.

Many two-product parameters obtained have been acquired in a chamber at a single temperature and under "dry" conditions (i.e., very low relative humidity (RH)). Extrapolations of $K_{\mathrm{p}, i}$ values for a given OPM composition to another temperature under dry conditions have proceeded using the Clausius-Clapeyron equation with an estimate of the enthalpy of vaporization $\left(\Delta H_{\mathrm{vap}, i}\right)$ for each hypothetical lumped product (Sheehan and Bowman, 2001). Utilizing chamber data in a theoretical consideration of the effects of $\mathrm{RH}$ is more difficult, and is a topic of this work.

In a chamber study of the oxidation of a mix of parent HCs, Odum et al. (1997) sought to predict the amount of OPM formed by using the collection of two-product $\alpha_{i}$ and $K_{\mathrm{p}, i}$ values measured for oxidation of the individual parent HCs. This approach implicitly assumes similarity in both the MW and the polarity characteristics of all the various two-product compounds so that in the OPM formed from all mixes of parent $\mathrm{HCs}, \overline{\mathrm{MW}}$ remains approximately constant and all $\zeta_{i} \approx 1$. Pankow and Barsanti (2009) have designated this the " $N \cdot 2 \mathrm{p}$ approach"; its range of applicability in the atmosphere remains uncertain, but nevertheless the
$N \cdot 2 \mathrm{p}$ approach has been widely utilized in the prediction of secondary OPM levels in the ambient atmosphere (e.g., Hoffman et al., 1997; Kanakidou et al., 2000; Pun et al., 2001;Tsigaridis and Kanakidou, 2003).

The computational advantage of the $N \cdot 2 \mathrm{p}$ approach in 3$\mathrm{D}$ air quality models (e.g., as in MADRID 1 as described by Pun et al., 2001) may be understood as follows. Any multicomponent G/P model requires an iterative solution to determine the PM composition and level at each point in space and time. The $N \cdot 2 \mathrm{p}$ approach assumes a limited number of secondary products, and provides a fixed $K_{\mathrm{p}, i}$ value for each $i$ for each iteration cycle at the $T$ of interest. In contrast, if the $K_{\mathrm{p}, i}$ values were allowed to vary because of dependence of the $\zeta_{i}$ and $\overline{\mathrm{MW}}$ on PM composition, then each solution within the series of solutions performed during each iteration cycle would require added computation time to estimate the $\zeta_{i}$ and $\overline{\mathrm{MW}}$ for the PM phase. Bowman and Melton (2004) compare the computational requirements of a number of $\zeta_{i}$ prediction methods, including the UNIFAC method of Fredenslund et al. (1975); UNIFAC was found to have the highest computational requirement.

Parent HCs considered in the MADRID 1 model are known to produce oxidation products with a range of polarities. For example, $\alpha$-pinene quickly leads to products like hydroxyacids and diacids that contain moderate polarity, while humulene initially leads to products of considerably lower polarity. The current assumption within MADRID 1 that all $\zeta_{i}=1$ for the OPM from all mixes of parent HCs is thus problematic. Bowman and Melton (2004) have concluded that assuming all $\zeta_{i}=1$ for a diesel soot partitioning system can result in $K_{\mathrm{p}, i}$ values that are 30 times higher than those measured experimentally. Moreover, the assumption that the organic portion of the PM formed is essentially free of water will certainly be in error whenever a significant portion of the PM is comprised of relatively high polarity compounds, and the RH is not low. In such circumstances, RH-driven water uptake into the PM phase can occur, further affecting $\zeta_{i}$ values (especially of the lower polarity products), and the value of $\overline{\mathrm{MW}}$. (A consideration of the potential magnitude of the effects of changing RH on PM levels at high $\Delta \mathrm{HC}$ values $\left(244\right.$ to $\left.501 \mu \mathrm{g} \mathrm{m}^{-3}\right)$ is provided by Seinfeld et al. (2001) for the ozone oxidation of several different biogenic HCs as well as cyclohexene.) Also, increasing RH levels will increase the likelihood of phase separation in the PM, especially whenever the OPM contains significant mass fractions of both SOA and POA compounds: the generally significant polarities of the former contrast with the generally low polarities of the latter. When phase separation does occur, a phase index $\theta$ is needed, with $\theta=\alpha$ referring to a relatively more polar, hydrophilic phase ( $\alpha$ mnemonically suggesting "aqueous"), and $\theta=\beta$ referring to the relatively less polar, less hydrophilic phase (Erdakos and Pankow, 2004). When the possibility of variation in the $\zeta_{i}$ and $\overline{\mathrm{MW}}$ and the possibility of phase separation are added to the $N \cdot 2 \mathrm{p}$ approach, the result 
is referred to as the $(N \cdot 2 \mathrm{p})^{\zeta_{p} \overline{\mathrm{MW}}, \theta}$ approach or simply the $N \cdot 2 \mathrm{p}$ approach (Pankow and Barsanti, 2009).

With a superscript $*$ also (coincidentally) used to denote a value determined under particular chamber conditions with a specific parent HC, Bowman and Karamalegos (2002) employ Eq. (1) to extrapolate a $K_{\mathrm{p}, i}^{*}$ to different conditions. In the $2 \mathrm{p}$ view, the OPM formed from a given parent $\mathrm{HC}$ could be composed of significant amounts of both lumped compounds. Thus, given the level of approximation already allowed in that view, it may be reasonable to assume that $\zeta_{i}^{*} \approx 1$ for both products in that OPM. For partitioning to a significantly different type of OPM, however, it may be that $\zeta_{i} \neq 1$. Thus, with $\overline{\mathrm{MW}}$ and $T$ also subject to variation, a $K_{\mathrm{p}, i}^{*}$ value may be extrapolated using the ratios: a) $\zeta_{i}^{*} / \zeta_{i} \approx 1 / \zeta_{i}$; b) $\overline{\mathrm{MW}}^{*} / \overline{\mathrm{MW}}$; c) $T / T^{*}$; and d) $p_{\mathrm{L}, i}^{\mathrm{o}}\left(T^{*}\right) / p_{\mathrm{L}, i}^{\mathrm{o}}(T)$. Assuming that $\Delta H_{\mathrm{vap}, i}$ is constant over the temperature interval of interest (i.e., from $T^{*}$ to $T$ ), correction for the effect of $T$ on $p_{\mathrm{L}, i}^{\mathrm{o}}$ occurs according to the integrated Clausius-Clapeyron equation which gives $p_{\mathrm{L}, i}^{\mathrm{o}}\left(T^{*}\right) / p_{\mathrm{L}, i}^{\mathrm{o}}(T)=\exp \left[\Delta H_{\mathrm{vap}, i}(1 / T-\right.$ $\left.1 / T^{*}\right)$ ]. Assuming that $f=1$, the overall result is (Bowman and Karamalegos, 2002)

$K_{\mathrm{p}, i}\left(T, x_{i}, x_{2}, x_{3}, \ldots x_{n}\right)$

$=K_{\mathrm{p}, i}^{*}\left(\frac{\overline{\mathrm{MW}}^{*}}{\overline{\mathrm{MW}}}\right)\left(\frac{1}{\zeta_{i}}\right)\left(\frac{T}{T^{*}}\right) \exp \left[\frac{\Delta H_{\mathrm{vap}, i}}{R}\left(\frac{1}{T}-\frac{1}{T^{*}}\right)\right]$

where $K_{\mathrm{p}, i}\left(T, x_{i}, x_{2}, x_{3}, \ldots x_{n}\right)$ here denotes that $K_{\mathrm{p}, i}$ depends on $T$ and on the PM composition, the latter being characterized by the set of mole fraction values $x_{j}$. Equation (2) has been applied in global modeling of SOA in the troposphere by Tsigaridis and Kanakidou (2003), with the needed $\zeta_{i}$ values estimated using the Wilson (1964) equation. However, while Tsigaridis and Kanakidou (2003) demonstrate the computational practicality of using Eq. (2) in a large-scale 3 -D model with the Wilson equation used for the $\zeta_{i}$ corrections, the Wilson equation parameters were assigned without regard to probable compound structure and functionality.

This work has four goals: 1) assign reasonable, specific surrogate structures to 25 lumped secondary compounds pertaining to a range of parent HCs of interest, and to 15 surrogate primary OPM compounds; 2) develop and implement a Wilson-equation-based group contribution method for prediction of $\zeta_{i}$ values for use with the 40 surrogate compounds that is computationally more economical than UNIFAC; 3) relax four key assumptions of the $N \cdot 2 \mathrm{p}$ approach (all $\zeta_{i}=1$; no RH effects; $\overline{\mathrm{MW}}=$ constant; and a single OPM phase) thereby permitting use of the $(N \cdot 2 \mathrm{p})^{\zeta_{p} \overline{\mathrm{MW}}, \theta}$ approach; then 4$)$ use the $(N \cdot 2 \mathrm{p})^{\zeta_{p}} \overline{\mathrm{MW}}, \theta$ approach to calculate OPM formation in selected cases using: a) experimentally determined or estimated values of the $K_{\mathrm{p}, i}^{*}$; b) Eq. (2); c) the assigned chemical structures; and d) the $\zeta_{i}$ prediction method developed here. For comparison, calculations were also made using the $N \cdot 2 \mathrm{p}$ approach.

\section{Methods}

\subsection{Partitioning SOA compounds}

A total of 25 lumped secondary products were considered to arise from a total of $14 \mathrm{HC}$ oxidation processes. Based on Odum et al. (1996), Griffin et al. (1999), Pun et al. (2003), Henze et al. (2006), and R. J. Griffin (personal communication, 2007), 11 of the processes assume two lumped products, and three of the processes $\left(\beta\right.$-pinene reacting with $\mathrm{NO}_{3}$ radical, humulene reacting with $\mathrm{OH}$ radical, and an $n$-alkane $\left(\mathrm{C}_{16}\right)$ reacting with $\mathrm{OH}$ radical) assume one lumped product each. Reaction (13) (a 2-ring polycyclic aromatic hydrocarbon (PAH) with $\mathrm{OH})$ and Reaction (14) $\left(\mathrm{C}_{16} n\right.$-alkane with $\mathrm{OH})$ were included as representative secondary reactions involving intermediate volatility parent $\mathrm{HC}$ compounds. Table 1 summarizes the information on the final set of the 40 surrogate compounds considered (25 lumped secondary products and 15 primary compounds).

As noted above, if $\zeta_{i}$ values are to be estimated in a mixture of interest, specific structural information is required for the compounds in the mixture. R. J. Griffin (personal communication, 2007) and this study considered known gas phase reaction mechanisms and kinetics (Griffin et al., 1999, 2002a, b, 2003; Surratt et al., 2006) to obtain the assignments for each lumped secondary product used in Table 1 for: 1) number of carbon atoms $v_{\mathrm{C}, i} ; 2$ ) whether cyclic or acyclic; 3) whether aromatic; and 4) retention (or not) of a double bond found in the parent HC. As summarized in Eq. (5) below, a corresponding initial estimate of $\mathrm{MW}_{i}$ was then assigned herein for each lumped product compound. Then, as summarized in Eq. (6) below, an initial estimate of $\overline{\mathrm{MW}}^{*}$ was computed as the mean of the $\mathrm{MW}_{i}$ estimates for the lumped products (two or one) from a given $\mathrm{HC}$ oxidation reaction (for two lumped products, this is equivalent to assuming that the OPM can be approximated as a 1:1 molar mixture of the two products). An initial estimate of each $\log _{10} p_{\mathrm{L}, i}^{\mathrm{o}}\left(T^{*}\right)^{\text {chamber }}$ was then obtained as summarized in Eq. (7) below, i.e., as based on Eq. (1) and $K_{\mathrm{p}, i}^{*}\left(T^{*}\right)$ at $T^{*}$ using the $\overline{\mathrm{MW}}^{*}$ estimate and assuming $\zeta_{i}^{*} \approx 1$ for each lumped product (see discussion preceding Eq. 2).

With the task denoted in Eq. (7) below completed, an approximation of the specific functionality was needed for each of the 25 surrogate secondary compounds (ultimately, for use as input to the $\zeta_{i}$ prediction method). The approach taken was to utilize known relationships between $p_{\mathrm{L}, i}^{\mathrm{o}}$ values and structure. For organic compounds, $p_{\mathrm{L}, i}^{\mathrm{o}}$ values decrease as $\nu_{\mathrm{C}, i}$ increases, and as compound polarity increases. In SIMPOL.1, which is a simple group-contribution model for prediction of $p_{\mathrm{L}, i}^{\mathrm{o}}(\mathrm{atm})$ values, Pankow and Asher (2008) write

$\log _{10} p_{\mathrm{L}, i}^{\mathrm{o}}(T)=\sum_{k} v_{k, i} b_{k}(T) \quad k=0,1,2,3, \quad$ etc.

where: $v_{k, i}$ is the number of groups of type $k$ in compound $i$; $b_{k}(T)$ is the $T$-dependent contribution to $\log _{10} p_{\mathrm{L}, i}^{\mathrm{o}}(T)$ from 
Table 1. Assumed properties of $25 \mathrm{SOA}$ and 15 POA surrogate compounds, and water.

\begin{tabular}{|c|c|c|c|c|c|c|c|c|c|c|c|c|}
\hline \multirow[b]{2}{*}{ compound } & \multicolumn{2}{|c|}{ SOA compounds } & \multirow[b]{2}{*}{ oxidant } & \multicolumn{4}{|c|}{ chamber-derived parameters } & \multirow[b]{2}{*}{$\begin{array}{c}\overline{\mathrm{MW}}^{* \mathrm{a}} \\
\left(\mathrm{g} \mathrm{mol}^{-1}\right)\end{array}$} & \multirow[b]{2}{*}{$\begin{array}{c}\mathrm{MW}_{i}^{\mathrm{b}} \\
\left(\mathrm{g} \mathrm{mol}^{-1}\right)\end{array}$} & \multicolumn{2}{|c|}{ other parameters } & \multirow[b]{2}{*}{$\begin{array}{l}p_{\mathrm{L}}^{\mathrm{o}}\left(T^{*}\right)^{\mathrm{e}} \\
\quad(\mathrm{atm})\end{array}$} \\
\hline & reaction & parent $\mathrm{HC}$ & & $\begin{array}{l}T^{*} \\
(\mathrm{~K})\end{array}$ & $K_{\mathrm{p}, i}^{*}\left(T^{*}\right)$ & $\alpha_{i}$ & ref. & & & $\begin{array}{l}\text { CP-Wilson. } 1 \\
\text { parameter } C_{i}^{\mathrm{d}}\end{array}$ & $\begin{array}{c}\Delta H_{\mathrm{vap}}(303)^{\mathrm{e}} \\
\left(\mathrm{kJ} \mathrm{mol}^{-1}\right)\end{array}$ & \\
\hline $\mathrm{S} 1$ & \multirow{2}{*}{1} & \multirow{2}{*}{$\alpha$-pinene } & \multirow{2}{*}{$\mathrm{OH}$} & \multirow{2}{*}{310} & 0.171 & 0.038 & \multirow[b]{2}{*}{ A } & 189 & 188 & 70.90 & 99.1 & $7.38 \mathrm{E}-10$ \\
\hline $\mathrm{S} 2$ & & & & & 0.004 & 0.326 & & 189 & 190 & 59.07 & 85.7 & $3.82 \mathrm{E}-08$ \\
\hline S3 & \multirow[b]{2}{*}{2} & \multirow{2}{*}{$\alpha$-pinene } & \multirow[b]{2}{*}{$\mathrm{O}_{3}$} & \multirow{2}{*}{310} & 0.088 & 0.125 & \multirow[b]{2}{*}{ A } & 194 & 214 & 41.76 & 74.3 & $1.34 \mathrm{E}-09$ \\
\hline $\mathrm{S} 4$ & & & & & 0.0788 & 0.102 & & 194 & 174 & 69.75 & 89.7 & $1.52 \mathrm{E}-09$ \\
\hline S5 & \multirow{2}{*}{3} & \multirow{2}{*}{$\beta$-pinene } & \multirow{2}{*}{$\mathrm{OH}$} & \multirow{2}{*}{310} & 0.044 & 0.13 & \multirow{2}{*}{ A } & 179 & 186 & 56.44 & 100.6 & $3.63 \mathrm{E}-09$ \\
\hline S6 & & & & & 0.0049 & 0.041 & & 179 & 172 & 52.63 & 78.6 & $2.75 \mathrm{E}-08$ \\
\hline S7 & \multirow[b]{2}{*}{4} & \multirow{2}{*}{$\beta$-pinene } & \multirow[b]{2}{*}{$\mathrm{O}_{3}$} & \multirow{2}{*}{310} & 0.195 & 0.026 & \multirow[b]{2}{*}{ A } & 188 & 202 & 56.92 & 103.9 & $7.32 \mathrm{E}-10$ \\
\hline S8 & & & & & 0.003 & 0.485 & & 188 & 174 & 64.41 & 77.1 & $4.18 \mathrm{E}-08$ \\
\hline S9 & 5 & $\beta$-pinene & $\mathrm{NO}_{3}$ & 310 & 0.0163 & 1.000 & A & 245 & 245 & 69.29 & 80.3 & $7.61 \mathrm{E}-09$ \\
\hline $\mathrm{S} 10$ & \multirow{2}{*}{6} & & & 205 & 0.0086 & 0.232 & P & 177 & 136 & 52.68 & 90.3 & $1.36 \mathrm{E}-08$ \\
\hline S11 & & isoprene & $\mathrm{OH}$ & 295 & 1.62 & 0.029 & B & 177 & 218 & 76.27 & 87.5 & $8.68 \mathrm{E}-11$ \\
\hline S12 & & & & & 0.055 & 0.239 & & 195 & 188 & 51.90 & 79.8 & $2.33 \mathrm{E}-09$ \\
\hline S13 & 7 & limonene & $\mathrm{OH}$ & 310 & 0.0053 & 0.363 & A & 195 & 202 & 43.32 & 90.0 & $2.57 \mathrm{E}-08$ \\
\hline S14 & & & & & 0.174 & 0.045 & & 152 & 146 & 32.46 & 105.5 & $1.06 \mathrm{E}-09$ \\
\hline S15 & 8 & ocimene & OH & 310 & 0.0041 & 0.149 & A & 152 & 158 & 37.15 & 90.2 & $3.36 \mathrm{E}-08$ \\
\hline S16 & 0 & & OH & 210 & 0.081 & 0.091 & $\Delta$ & 174 & 202 & 62.45 & 111.3 & $1.46 \mathrm{E}-09$ \\
\hline S17 & 9 & terpinene & OH & 310 & 0.0046 & 0.367 & A & 174 & 146 & 24.88 & 79.7 & $3.52 \mathrm{E}-08$ \\
\hline $\mathrm{S} 18$ & & & & & 0.053 & 0.071 & & 173 & 148 & 38.63 & 95.6 & $2.54 \mathrm{E}-09$ \\
\hline S19 & 10 & toluene & $\mathrm{OH}$ & 310 & 0.0019 & 0.138 & $\mathrm{C}, \mathrm{D}$ & 173 & 197 & 48.12 & 81.4 & $8.21 \mathrm{E}-08$ \\
\hline S20 & 11 & Lulon & คH & 210 & 0.042 & 0.038 & $C D$ & 187 & 176 & 31.03 & 87.5 & $2.64 \mathrm{E}-09$ \\
\hline $\mathrm{S} 21$ & 11 & xylene & $\mathrm{OH}$ & 310 & 0.0014 & 0.167 & $\mathrm{C}, \mathrm{D}$ & 187 & 197 & 48.12 & 81.4 & $8.21 \mathrm{E}-08$ \\
\hline S22 & 12 & humulene & $\mathrm{OH}$ & 310 & 0.0501 & 1.000 & A & 270 & 270 & 72.94 & 73.9 & $1.80 \mathrm{E}-09$ \\
\hline $\mathrm{S} 23$ & & & & & 0.015 & 1.000 & & 175 & 186 & 68.19 & 94.5 & $8.14 \mathrm{E}-09$ \\
\hline $\mathrm{S} 24$ & 13 & 2-ring PAH & $\mathrm{OH}$ & 298 & 0.002 & 1.000 & $\mathrm{E}$ & 175 & 164 & 47.75 & 81.5 & $7.05 \mathrm{E}-08$ \\
\hline S25 & 14 & $\mathrm{C}_{16} n$-alkane & $\mathrm{OH}$ & 298 & 0.0229 & 1.000 & $\mathrm{E}$ & 301 & 301 & 94.58 & 100.9 & $3.28 \mathrm{E}-09$ \\
\hline
\end{tabular}

\begin{tabular}{|c|c|c|c|c|c|c|}
\hline \multicolumn{7}{|c|}{ POA compounds } \\
\hline Compound & & $K_{\mathrm{p}, i}^{*}(293)^{\mathrm{c}}$ & $\begin{array}{c}\mathrm{MW}_{i} \\
\left(\mathrm{~g} \mathrm{~mol}^{-1}\right)\end{array}$ & $\begin{array}{c}\text { CP-Wilson.1 } \\
\text { parameter } C_{i} \mathrm{~d}\end{array}$ & $\begin{array}{c}\Delta H_{\text {vap }}(303)^{\mathrm{e}} \\
\left(\mathrm{kJ} \mathrm{mol}^{-1}\right)\end{array}$ & $\begin{array}{l}p_{\mathrm{L}}^{\mathrm{o}}(293)^{\mathrm{e}} \\
\quad(\mathrm{atm})\end{array}$ \\
\hline $\mathrm{P} 1$ & 2,6-naphthalene diacid & 101.7 & 216 & 69.62 & 118.9 & $1.09 \mathrm{E}-12$ \\
\hline $\mathrm{P} 2$ & benzo[ghi]perylene & 43.83 & 276 & 119.40 & 112.7 & $1.99 \mathrm{E}-12$ \\
\hline P3 & butanedioic acid & 0.0025 & 118 & 26.59 & 84.0 & $8.31 \mathrm{E}-08$ \\
\hline $\mathrm{P} 4$ & $17(\alpha) \mathrm{H}-21(\beta) \mathrm{H}$-hopane & 72.83 & 412 & 172.24 & 123.1 & $8.01 \mathrm{E}-13$ \\
\hline P5 & $n$-nonacosane & 33.62 & 409 & 166.96 & 149.2 & $1.75 \mathrm{E}-12$ \\
\hline P6 & octadecanoic & 1.142 & 284 & 107.03 & 123.4 & $7.41 \mathrm{E}-11$ \\
\hline P7 & phthalic acid & 0.4801 & 166 & 47.60 & 101.4 & $3.01 \mathrm{E}-10$ \\
\hline P8 & UCM2 (unresolved complex mixture 2) & 10.45 & 390 & 162.46 & 132.4 & $5.90 \mathrm{E}-12$ \\
\hline $\mathrm{P9}$ & monoglyceride & 434.0 & 330 & 123.00 & 138.8 & $1.68 \mathrm{E}-13$ \\
\hline $\mathrm{P} 10$ & triglyceride & $1.72 \mathrm{E}+17$ & 860 & 299.04 & 280.0 & $1.63 \mathrm{E}-28$ \\
\hline P11 & levoglucosan & 0.1670 & 162 & 57.14 & 94.4 & $8.88 \mathrm{E}-10$ \\
\hline $\mathrm{P} 12$ & UCM1 (unresolved complex mixture 1) & $1.42 \mathrm{E}-05$ & 210 & 87.12 & 79.2 & $8.07 \mathrm{E}-06$ \\
\hline $\mathrm{P} 13$ & UCM3 (unresolved complex mixture 3) & $1.64 \mathrm{E}+05$ & 487 & 202.35 & 158.2 & $3.01 \mathrm{E}-15$ \\
\hline $\mathrm{P} 14$ & hexadecanoic acid & 0.1427 & 256 & 95.49 & 114.3 & $6.58 \mathrm{E}-10$ \\
\hline P15 & glycerol & 0.0005 & 92 & 39.10 & 78.0 & $5.02 \mathrm{E}-07$ \\
\hline Water & $\mathrm{H}_{2} \mathrm{O}$ & & 18 & 7.15 & $\mathrm{~g}$ & $\mathrm{~g}$ \\
\hline
\end{tabular}

Footnotes: ${ }^{\mathrm{a}}$ Calculated as the mean of the inferred $\mathrm{MW}_{i}$ values; ${ }^{\mathrm{b}}$ Inferred based on chamber data using iterative process outlined in Eqs. (510). ${ }^{\mathrm{c}}$ Although these $K_{\mathrm{p}, i}$ values were not determined in chamber experiments, the asterisk is maintained for clarity regarding usage in Eq. (2). ${ }^{\mathrm{d}}$ Calculated based on Eq. (13). ${ }^{\mathrm{e}}$ Calculated based on parameters given in Pankow and Asher (2007). ${ }^{\mathrm{f}}$ Included for the sake of completeness, even though its $K_{\mathrm{p}, i}^{*}(293)$ value is so low that it will not contribute significantly to OPM levels. ${ }^{\mathrm{g}}$ Not required since all water calculations were made based on specified RH values.

References: A. Griffin et al. (1999); B. Henze and Seinfeld (2006); C. Odum et al. (1997); D. Pun et al. (2003); E. Estimated by CACM and MPMPO (Griffin. 2007). 
one group of type $k$. Equation (3) provides a means to assemble the aggregate effects of structure on $p_{\mathrm{L}, i}^{\mathrm{o}}(T)$. SIMPOL.1 utilizes a zeroeth group $(k=0)$, with $\nu_{0, i}=1$ for all $i$ and $b_{0}(293.15)=1.99$. The $k=1$ group pertains to molecular carbon; e.g., for hexane, $v_{1, i} \equiv v_{\mathrm{C}, i}=6$. Because $b_{1}(293.15) \equiv$ $b_{\mathrm{C}}(293.15)=-0.47$, within any given compound class, $p_{\mathrm{L}, i}^{\mathrm{o}}$ values decrease by $\sim 1 / 2$ order of magnitude for every unit increase in carbon number. And, $p_{\mathrm{L}, i}^{\mathrm{o}}$ can also be decreased for a given carbon skeleton by adding polar functional groups. Equation (3) may thus be re-written as

$\log _{10} p_{\mathrm{L}, i}^{\mathrm{o}}(T)=v_{0, i} b_{0}(T)+v_{\mathrm{c}, i} b_{\mathrm{c}}(T)+\omega_{i}(T)$

wherein all the structural aspects beyond carbon number are placed in the term $\omega_{i}(T)$. With $v_{0, i}=1$ and using the assumed value of $v_{\mathrm{C}, i}$, then $p_{\mathrm{L}, i}^{\mathrm{o}}\left(T^{*}\right)^{\text {chamber }}$ allows an estimate of $\omega_{i}\left(T^{*}\right)^{\text {chamber }}$ (see also Eq. 8 below). Four groups are of special interest: hydroxyl $\left(b_{7}(293.15) \equiv b_{\mathrm{OH}}(293.15)=-\right.$ $2.29)$; aldehyde $\left(b_{8}(293.15) \equiv b_{\mathrm{CHO}}(293.15)=-1.06\right)$; ketone $\left(b_{9}(293.15) \equiv b_{\mathrm{CO}}(293.15)=-0.99\right)$; and carboxylic acid $\left(b_{10}(293.15) \equiv b_{\mathrm{COOH}}(293.15)=-3.59\right)$. Thus, for example, the conversion of cyclohexene to adipic acid is accompanied by about a seven order of magnitude drop in $\log _{10} p_{\mathrm{L}, i}^{\mathrm{o}}(293.15)$.

Compound-to-compound differences in polarity are the primary drivers of differences among the $\zeta_{i}$ values in a mixture. Considering the groups that contribute significantly to $\omega_{i}(T)$ by adding polarity to a molecule (e.g., the four groups noted above, nitrate $\left(\mathrm{ONO}_{2}\right)$, nitrite $\left.\left(\mathrm{NO}_{2}\right)\right)$, as well as other structural groups assumed to be retained from the parent $\mathrm{HC}$ (e.g., rings), the goal was to manually vary the $v_{k, i}$ to obtain an estimate of $\omega_{i}\left(T^{*}\right)^{\text {fitted }}$ that would match $\omega_{i}\left(T^{*}\right)^{\text {chamber }}$ (see Eq. 9). The goal was to thereby derive a reasonable approximation of the overall polarity for each surrogate lumped secondary product for subsequent use in $\zeta_{i}$ prediction . Each resulting new $v_{k, i}$ set (including $v_{\mathrm{C}, i}$ ) implied a new $\mathrm{MW}_{i}$ for the lumped product. When executed in concert with the other lumped product (if it exists) from each particular parent HC, as summarized in Eq. (10) below the process led to updated estimates of the $\mathrm{MW}_{i}$ and $\overline{\mathrm{MW}}^{*}$. Consequently, the approach used led naturally to an iterative process producing a possible best-fit $v_{k, i}$ set for each lumped product.

The overall scheme by which the values of each $v_{k, i}$ set were assigned is summarized below. (The character " $\rightarrow$ " should be read as "gives".)

$\nu_{\mathrm{C}, i} \rightarrow \mathrm{MW}_{i}$

$\mathrm{MW}_{i} \rightarrow \overline{\mathrm{MW}}^{*}$ estimated as the simple mean of the $\mathrm{MW}_{i}$ values from Eq. (5)

$\overline{\mathrm{MW}}^{*}$ with $K_{\mathrm{p}, i}^{*}\left(T^{*}\right) \rightarrow$ estimate of $p_{\mathrm{L}, i}^{\mathrm{o}}\left(T^{*}\right)^{\text {chamber }}$

by Eq. (1), with $\zeta_{i}^{*}=1$
$p_{\mathrm{L}, i}^{\mathrm{o}}\left(T^{*}\right)^{\text {chamber }}$ with $\nu_{0, i}$ and $\nu_{\mathrm{C}, i} \rightarrow \omega_{i}\left(T^{*}\right)^{\text {chamber }}$

by Eq. (4)

$\omega_{i}\left(T^{*}\right)^{\text {chamber }} \rightarrow$ fitted $v_{k, i}$ set $\rightarrow \omega_{i}\left(T^{*}\right)^{\text {fitted }}$

by inverse application of Eq. (4)

fitted $v_{k, i}$ set (including $\nu_{\mathrm{C}, i}$ ) $\rightarrow \mathrm{MW}_{i}$

Boxed values represent quantities that were held fixed during the iteration. A set of preliminary structures for the 25 SOA surrogate compounds obtained prior to full convergence of the process is given in the Supplementary Materials (http://www.atmos-chem-phys.net/10/5475/2010/ acp-10-5475-2010-supplement.zip). At the end of the process, for every surrogate SOA product, the iteration yielded two converged values of $\omega_{i}(T)$, namely $\omega_{i}\left(T^{*}\right)^{\text {chamber }}$ and $\omega_{i}\left(T^{*}\right)^{\text {fitted: }}$ the agreement was within a few percent in every case. Even though binary mixtures of different compounds will not in general reflect ideality, the $N \cdot 2 \mathrm{p}$ assumption of $\zeta_{i}=1$ was maintained throughout the iteration (see Eq. 7). However, because a $\zeta_{i}$ prediction method such as CPWilson. 1 will not in general yield $\zeta_{i}=1$ in any OPM mixture, after the fitting, results obtained for one parent $\mathrm{HC}$ using the $(N \cdot 2 \mathrm{p})^{\zeta_{p} \overline{\mathrm{MW}}, \theta}$ approach will not collapse at $\mathrm{RH}=0 \%$ to the corresponding $2 \mathrm{p}$ results if that parent $\mathrm{HC}$ is considered to lead to two products.

The final assumed structures for the surrogate SOA products are given in Fig. 1; corresponding inferred molecular parameters are given in Table 1. While there is some arbitrariness in the selection of each final $v_{k, i}$ set and the corresponding structure(including the insertion of ether linkages to fine tune the $\omega_{i}(T)$ fit), this is not considered problematic given the considerable approximations that are already built into the $2 \mathrm{p}$ model: simply finding a structure that matches the value of $\omega_{i}(T)$ derived using Eq.(4) provides meaningful insight regarding aggregate compound polarity that can be used to predict $\zeta_{i}$ effects in OPM systems.

\subsection{Partitioning POA compounds}

15 POA surrogate compounds (P1-P15) were selected to cover a broad range of source types; all 15 compounds were considered subject to G/P partitioning (Fig. 1). Structures for P1-P8 were obtained from Griffin et al. (2003) for mobile (P1-4, P7), mobile/natural (P5), and general cooking (P6) sources. P9, P10, and P15 were selected based on Nolte et al. (1999) as being relevant for meat cooking sources. Levoglucosan (P11) was selected as relevant for biomass burning (Simoneit et al., 2000; Fraser et al. 2002; Zhao et al., 2007). P8, P12, and P13 were selected as representatives of unresolved complex mixture (UCM) materials found in primary mobile emissions. P8 was considered by Griffin et al. (2003). P12 and P13 were included here to expand the volatility range of UCM related materials considered. 

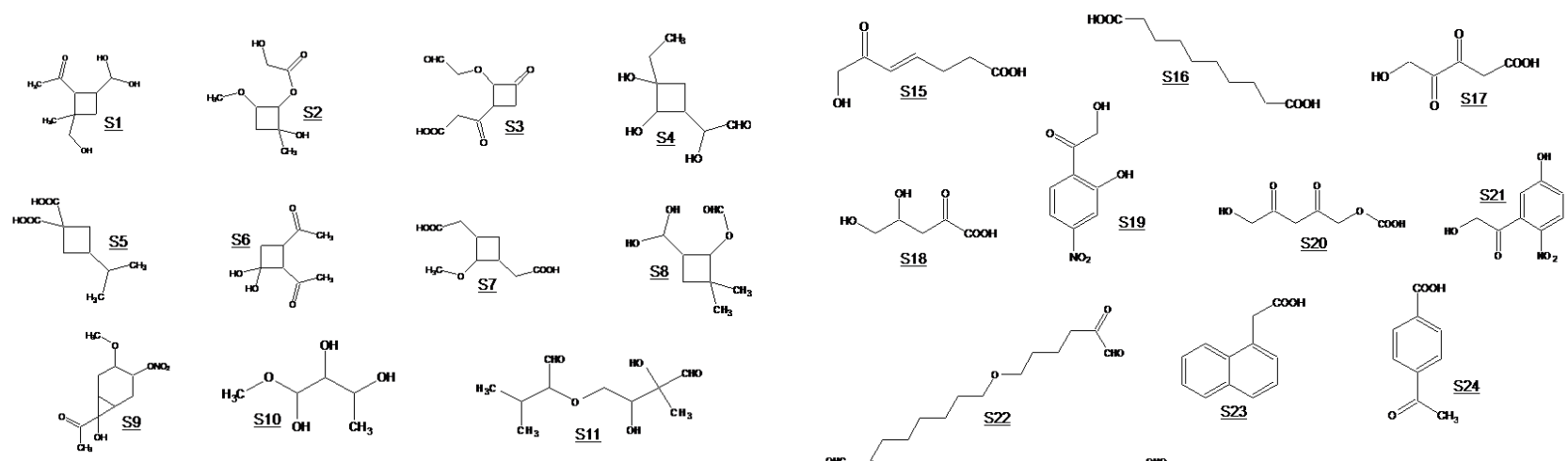

(a)<smiles>CC(C)CC(C)C(C)CC(C)C</smiles>

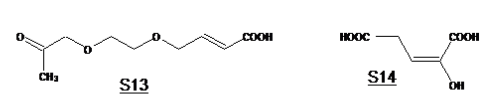

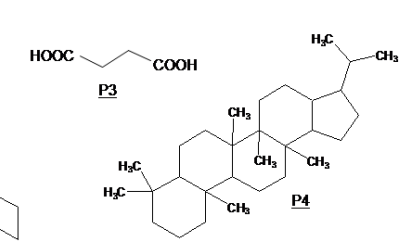

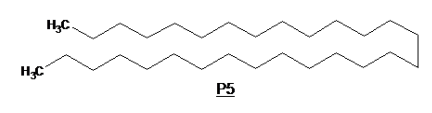

Hec
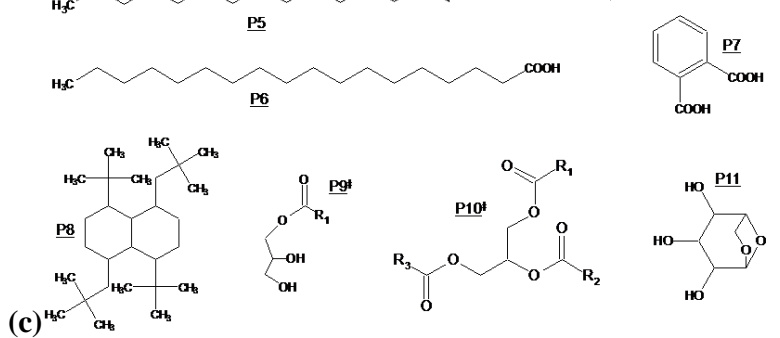

(c) ${ }^{\text {मc }}$

(d)
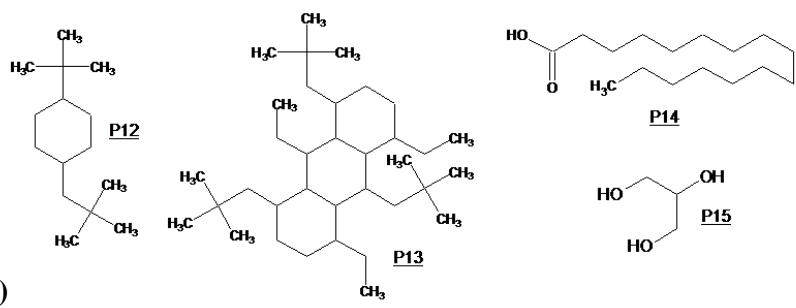

(b)

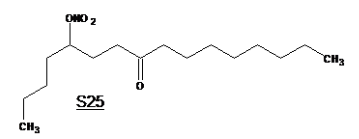

Fig. 1. Molecular structures of lumped SOA products and surrogate POA compounds. ${ }^{\ddagger} R_{1}=C_{15}$ alkyl chain; $R_{2}=C_{17}$ alkyl chain; $R_{3}=C_{17}$ alkyl chain with one double bond. For some structures, ether linkages have been included to fine tune the estimated polarity, even when such linkages may be unlikely consequences of the relevant oxidation reactions.

\subsection{Chang-Pankow-Wilson (CP-Wilson) activity coeffi- cient method}

\subsubsection{Equations}

The approach developed here to calculate $\zeta_{i}$ values is based on the equation of Wilson (1964), with modifications introduced for use in a group-contribution manner and for consideration of $T$ effects by application of a $1 / T$ factor as suggested by the Scatchard-Hildebrand equation (Flory, 1953). For each neutral compound $i$ in a mixture of other such compounds, each group is therefore assumed here to contribute additively to $\zeta_{i}$ according to

$\ln \zeta_{i}=\frac{\sum_{k}\left(-n_{k, i} \ln \Gamma_{k}\right)-C_{i}}{T / 300}$

where: $n_{k, i}$ is the number of groups of type $k$ in $i ; \Gamma_{k}$ is the activity coefficient of group $k$; and $C_{i}$ is a compound specific constant that functions as a reference-state correction term. While $k$ is again used as the group index for the summation, the set of groups used for the CP-Wilson method with coefficients $n_{k, i}$ is not synonymous with the set used by Asher and Pankow (2007) with coefficients $v_{k, i}$.

The equation for $\Gamma_{k}$ is assumed here to take the same form as that originally proposed by Wilson (1964) so that

$\ln \Gamma_{k}=-\ln \left(\sum_{j} x_{j} \Lambda_{k j}\right)+1-\sum_{l} \frac{x_{l} \Lambda_{l k}}{\sum_{j} x_{j} \Lambda_{l j}}$

The summations occur over all groups in the mixture wherein: $j$ and $l$ providing indexing through the groups; $x_{j}$ is the group mole fraction; and $\Lambda_{k j}$ is the interaction parameter between groups $k$ and $j$. For each compound $i$, the constant $C_{i}$ is evaluated according to

$C_{i}=\sum_{k} n_{k, i} \ln \Gamma_{k}^{(i)}$ 
where $\Gamma_{k}^{(i)}$ is the activity coefficient of group $k$ in pure $i$ and is evaluated using Eq. (12). Equations (11-13) compose the $\mathrm{CP}-W i l s o n$ method. Values of $C_{i}$ for the compound structures considered here are given Table 1 .

In its original form, the Wilson equation is less general than the CP-Wilson method because it is not a groupcontribution method. Rather, it handles each compound in the mixture as a full chemical entity, and so its implementation requires specific chemical property information for all the compounds in the mixture. This poses an obvious problem for atmospheric applications: even if the composition of a given atmospheric OPM sample could be accurately characterized, the property information needed for use with the Wilson equation would not be available, not even for some appropriate list of lumped/surrogate compounds. The group contribution approach utilized in the CP-Wilson method overcomes this problem: this method only requires parameter information for the constituent groups, and not property data for all compounds of interest. In general, the CP-Wilson method will be significantly faster than UNIFAC because it requires fewer logarithm and double summation operations, and because the empirical treatment for the $T$ dependence in Eq. (11) allows the $C_{i}$ to be computed once, and thereafter acquired from a look-up table.

\subsubsection{Parameter fitting for CP-Wilson.1}

The parameter values needed for a group contribution method are generally obtained by a fitting that minimizes some measure of the difference, for the parameter of interest, between: a) the group-contribution predicted values; vs. b) corresponding experimental values. The particular fitting parameters obtained here combined with the governing equations compose version CP-Wilson.1. Ideally, the fit carried out here would utilize experimental $\zeta_{i}$ values obtained for mixtures involving compounds similar to those of interest. Since such experimental data are not currently available, UNIFAC-generated values (i.e., $\zeta_{i}^{\mathrm{U}}$ values) were used as the best, readily available substitute. The $\zeta_{i}^{\mathrm{U}}$ values were obtained for mixtures involving compounds with the mix of functionalities and structures of interest, plus water. For SOA compounds, the preliminary structures given in the Supplementary Materials (http://www.atmos-chem-phys. net/10/5475/2010/acp-10-5475-2010-supplement.zip) were used; for the POA compounds, the structures in Fig. 1 were used. While the nitrate $\left(\mathrm{ONO}_{2}\right)$ group is an SOA functionality of interest here, it is not currently a UNIFAC group, and needed experimental thermodynamic data do not exist. The UNIFAC group $\mathrm{CHNO}_{2}$ was therefore substituted for nitrate during the fitting. The predictions based on CP-Wilson. 1 are thus probably least reliable for the lumped SOA compounds that contain the nitrate group. Overall, fitting to $\zeta_{i}^{\mathrm{U}}$ values was considered adequate given the high general merits of the UNIFAC method, and because use of the $2 p$ model and the assumed structures for the SOA compounds (Fig. 1) already represents a significant degree of approximation. At some future point, the CP-Wilson method could be re-fit using the extensive experimental $\zeta_{i}$ data set used by Fredenslund et al. (1975) to fit the UNIFAC method, and using new data for organic nitrate compounds (see above), the result perhaps designated as version CP-Wilson.2.

A total of $13338 \zeta_{i}^{\mathrm{U}}$ values were generated for various binary mixtures of the 41 compounds ( 40 organic compounds and water) over the mole fraction range 0.2 to 0.8 within the temperature range -10 to $50^{\circ} \mathrm{C}$. Although some of these mixtures are not stable (i.e., would exhibit phase separation), that did not affect the inherent utility of the associated $\zeta_{i}^{\mathrm{U}}$ values. Parameter optimization was performed on the total of $441 \Lambda_{k j}$ parameters describing interactions among the 21 constituent groups. The fitting (optimization) occurred by use of the Levenberg-Marquardt algorithm (Levenberg, 1944) to minimize the function $\chi^{2}=\sum_{1}^{n}\left(1-\zeta_{i}^{\mathrm{CPW} .1} / \zeta_{i}^{\mathrm{U}}\right)^{2}$ wherein $n=13338$.

The optimization was performed in three stages. In the first stage, a subset containing $4446 \zeta_{i}^{\mathrm{U}^{\mathrm{V}}}$ values for mixtures at $20^{\circ} \mathrm{C}$ was extracted from the entire pool to perform a preliminary optimization. Seven different sets of initial values for the $\Lambda_{k}$ were involved in the fitting: all $\Lambda_{k j}=250$, all $\Lambda_{k j}=500$; all $\Lambda_{k j}=1000 ;$ all $\Lambda_{k j}=3000$; all $\Lambda_{k j}=5000$; all $\Lambda_{k j}=7000$; and all $\Lambda_{k j}=10000$. During the fitting runs, the $\Lambda_{k j}$ were restricted within $0<\Lambda_{k j}<10000$. (Due to the presence of the natural logarithm term in Eq. (12), it is required that each $\Lambda_{k j}>0$.) The mean and standard deviation of the seven $\chi^{2}$ were 228 and 205. The best fit yielded $\chi^{2}=24$ and $0<\Lambda_{k j}<6000$. The set of $\Lambda_{k j}$ yielding $\chi^{2}=24$ was further refined by performing 10 additional optimizations in which the initial $\Lambda_{k j}$ were varied randomly within $\pm 30 \%$, but still so that $0<\Lambda_{k j}<6000$. The resulting best fit yielded $\chi^{2}=22.8$. Consideration of other initial $\Lambda_{k j}$ sets outside the $\pm 30 \%$ range did not improve $\chi^{2}$. In the second fitting stage, an optimization involving the entire set of $13338 \zeta_{i}^{\mathrm{U}}$ values was performed five times using the best preliminary $\Lambda_{k j}$ fit, but randomly varying the values within $\pm 30 \%$ (but still so that $0<\Lambda_{k j}<6000$ ). The resulting $\chi^{2}$ range was 124 to 127. The $\Lambda_{k j}$ set giving $\chi^{2}=124$ was then used as input for a final optimization during which the step size was reduced three times. The resulting $\Lambda_{k j}$ set gave $\chi^{2}=120$; further reduction of the step size did not reduce $\chi^{2}$.

\section{$2.4(N \cdot 2 p)^{\zeta_{p} \overline{\mathrm{MW}}, \theta}$ approach implementation}

\subsubsection{Phase separation considerations}

Some of the surrogate compounds considered possess substantial polarity (e.g., the SOA products of isoprene with $\mathrm{OH}$ radical), and some are completely non-polar (e.g., the POA compound $n$-nonacosane). A liquid PM mixture containing significant proportions of both types of compounds will be unstable relative to phase separation (Erdakos and 
Pankow, 2004). At constant $P$ and $T$ in a one-phase liquid system, phase separation will tend to occur when the liquid can find a lower Gibbs free energy by separating into two phases. Similarly, in a gas+liquid system (also at constant $P$ and $T$ ) that is initially at equilibrium between the gas and a single-phase liquid, phase separation in the liquid will tend to occur when the overall system can find a lower Gibbs free energy by transformation into a three-phase system (a gas phase and two liquid phases); the transformation is likely to be accompanied by some net exchange with the gas phase of the partitioning compounds. All of the surrogate compounds considered here are hydrocarbons with varying degrees and types of added oxygen functionality. For systems comprised of such compounds, the maximum number of liquid phases is two. Following Erdakos and Pankow (2004), when two liquid phases exist, then $\theta=\alpha$ and $\beta$ (see above). $K_{\mathrm{p}, i}^{\theta}$ values were calculated by means of Eq. (2) using $K_{\mathrm{p}, i}^{*}$ values. For most of the SOA surrogate compounds, actual chamberderived $K_{\mathrm{p}, i}^{*}$ and $\alpha_{i}$ values were used. For three SOA surrogate compounds (S23, S24, and S25), because the experimental data were not available, the Caltech Atmospheric Chemistry Mechanism (Griffin et al., 2002) and the Model to Predict the Multi-phase Partitioning of Organics (MPMPO) (Griffin et al., 2003) were used to predict a yield versus organic PM mass concentration $\left(M_{\mathrm{o}}\right)$ curve so that $K_{\mathrm{p}, i}^{*}$ and $\alpha_{i}$ values could be predicted. For the POA surrogate compounds $(\mathrm{P} 1-\mathrm{P} 15)$, chamber-derived $K_{\mathrm{p}, i}^{*}$ do not exist, so $K_{\mathrm{p}, i}^{*}$ values were calculated directly by means of Eq. (1) assuming $\zeta_{i}=1$ and $\overline{\mathrm{MW}}=\mathrm{MW}_{i}$ and using the SIMPOL. 1 method of Pankow and Asher (2008) to estimate $p_{\mathrm{L}, i}^{\mathrm{o}}\left(T^{*}=293 \mathrm{~K}\right)$ based on structure.

\subsubsection{PM mass calculations}

All 40 lumped surrogate compounds and water were assumed subject to G/P partitioning. $F_{i}\left(\mu \mathrm{g} \mathrm{m}^{-3}\right)$ represents the PMassociated level of $i$. (The related parameter $F_{i}\left(\mathrm{ng} \mathrm{m}^{-3}\right)$ has been used in prior work from this group.) If two PM phases are present, then

$F_{i}=F_{i}^{\alpha}+F_{i}^{\beta}$

$T_{i}\left(=A_{i}+F_{i}\right)$ is the sum of the G- and total P-phase concentrations. At equilibrium the G-phase concentration $A_{i}$ $\left(\mu \mathrm{g} \mathrm{m}^{-3}\right)$ can be calculated based on the value of $K_{\mathrm{p}, i}$ and $F_{i}$. In the case of phase separation,

$T_{i}=\frac{F_{i}^{\theta}}{M_{\mathrm{TPM}}^{\theta} K_{\mathrm{p}, i}^{\theta}}+F_{i}$

wherein the first term on the RHS represents $A_{i}$, as based on equilibrium with either liquid phase $(\theta=\alpha$ or $\beta)$, whichever is more convenient. $M_{\mathrm{TPM}}^{\theta}\left(\mu \mathrm{g} \mathrm{m}^{-3}\right)$ represents the total mass concentration of the $\theta$ phase. In this work, a constant $\mathrm{RH}$ was assumed in each case considered. At equilibrium, the statement of equality of water activity between the gas and particle phases is

$$
\mathrm{RH} / 100=\zeta_{\mathrm{w}}^{\theta} x_{\mathrm{w}}^{\theta}
$$

which is thermodynamically equivalent to Eq. (1). As with Eq. (15), $\theta=\alpha$ or $\beta$, and in the absence of phase separation, the $\theta$ is dropped.

Iterational solutions of the overall $\mathrm{G} / \mathrm{P}$ distribution problem represented by Eqs. (14-16) were obtained by applying a liquid-liquid-equilibrium (LLE) flash calculation in each iteration as described by Chang and Pankow (2006). Using the index $\theta$ as needed, relationships used in consideration of the results are:

$$
M_{\mathrm{o}}^{\theta}=\sum_{\text {organic } i} F_{i}^{\theta}
$$

$M_{\mathrm{o}}=M_{\mathrm{o}}^{\alpha}+M_{\mathrm{o}}^{\beta}$

$M_{\mathrm{w}}=M_{\mathrm{w}}^{\alpha}+M_{\mathrm{w}}^{\beta}$

$M_{\mathrm{TPM}}=M_{\mathrm{o}}+M_{\mathrm{w}}=M_{\mathrm{TPM}}^{\alpha}+M_{\mathrm{TPM}}^{\beta}$

where: $M_{\mathrm{o}}^{\theta}\left(\mu \mathrm{g} \mathrm{m}^{-3}\right)$ is total organic mass concentration associated with phase $\theta ; M_{\mathrm{o}}\left(\mu \mathrm{g} \mathrm{m}^{-3}\right)$ is the total organic mass concentration over all PM phases; $M_{\mathrm{w}}^{\alpha}$ and $M_{\mathrm{w}}^{\beta}\left(\mu \mathrm{g} \mathrm{m}^{-3}\right)$ are the water mass concentrations associated with the $\alpha$ and $\beta$ phases; $M_{\mathrm{w}}\left(\mu \mathrm{g} \mathrm{m}^{-3}\right)$ is the total water mass concentration over all PM phases; and $M_{\mathrm{TPM}}\left(\mu \mathrm{g} \mathrm{m}^{-3}\right)$ is the total PM mass concentration. As noted in Eq. (20), for the systems considered here, $M_{\mathrm{TPM}}\left(\mu \mathrm{g} \mathrm{m}^{-3}\right)$ is considered to be comprised of organic compounds and water (and no salt), and a maximum of two phases.

\subsection{Cases}

\subsubsection{Computational efficiency (CE) test case (liquid phase only)}

For a given group-contribution $\zeta_{i}$ prediction method, PM properties that affect the computation time are the number of constituent groups and the number of compounds. Thus, a one-phase liquid mixture at $T=300 \mathrm{~K}$ was invoked containing water and 40 organic compounds (the 25 preliminary surrogate SOA compounds in the Supplementary Materials: http://www.atmos-chem-phys.net/10/5475/ 2010/acp-10-5475-2010-supplement.zip) and the 15 surrogate POA compounds in Fig. 1), all at $x_{i}=1 / 41$. The fact that such a system would not remain a single phase at equilibrium at $300 \mathrm{~K}$ was not a problem because the only issue was the speed of the $\zeta_{i}$ calculations. The speed of the calculations was compared for CP-Wilson. 1 vs. five existing $\zeta_{i}$ estimation methods, namely UNIFAC, NRTL (Renon and Prausnitz, 1968), TK-Wilson (Tsuboka and Katayama, 1975), UNIQUAC (Abram and Prausnitz, 1975), and the unmodified Wilson equation. For each method, the CPU time 
Table 2. Results for chamber-based (CB) cases with $\alpha$-pinene/ $\mathrm{O}_{3}$ as measured by Cocker et al. (2001) and as predicted using the approach and using the approach with the CP-Wilson.1 method for prediction of $\zeta_{i}$ values.

\begin{tabular}{|c|c|c|c|c|c|c|c|c|c|c|c|c|}
\hline \multirow[b]{2}{*}{ case } & \multirow[b]{2}{*}{$\begin{array}{c}T \\
(\mathrm{~K})\end{array}$} & \multirow[b]{2}{*}{$\begin{array}{c}\Delta \mathrm{HC} \\
\left(\mu \mathrm{g} \mathrm{m}^{-3}\right)\end{array}$} & \multirow[b]{2}{*}{$\begin{array}{l}\mathrm{RH} \\
(\%)\end{array}$} & \multirow{2}{*}{$\begin{array}{c}\text { Measured } \\
M_{\mathrm{TPM}} \\
\left(\mu \mathrm{g} \mathrm{m}^{-3}\right)\end{array}$} & \multicolumn{4}{|c|}{ Predictions } & \multicolumn{4}{|c|}{ Predictions } \\
\hline & & & & & $\begin{array}{c}M_{\mathrm{o}} \\
\left(\mu \mathrm{g} \mathrm{m}^{-3}\right)\end{array}$ & $\begin{array}{c}M_{\mathrm{W}} \\
\left(\mu \mathrm{g} \mathrm{m}^{-3}\right)\end{array}$ & $\begin{array}{c}M_{\mathrm{TPM}} \\
\left(\mu \mathrm{g} \mathrm{m}^{-3}\right)\end{array}$ & $\begin{array}{c}\text { error }^{\mathrm{a}} \text { in } \\
M_{\mathrm{TPM}}\end{array}$ & $\begin{array}{c}M_{\mathrm{o}} \\
\left(\mu \mathrm{g} \mathrm{m}^{-3}\right)\end{array}$ & $\begin{array}{c}M_{\mathrm{W}} \\
\left(\mu \mathrm{g} \mathrm{m}^{-3}\right)\end{array}$ & $\begin{array}{c}M_{\mathrm{TPM}} \\
\left(\mu \mathrm{g} \mathrm{m}^{-3}\right)\end{array}$ & $\begin{array}{c}\text { error }^{\mathrm{a}} \text { in } \\
M_{\mathrm{TPM}}\end{array}$ \\
\hline CB.1 & 301.8 & 386.3 & 41.0 & 86 & 82 & $0^{\mathrm{b}}$ & 82 & $-5 \%$ & 83 & 6 & 89 & $+3 \%$ \\
\hline CB. 2 & 301.8 & 675.0 & 57.7 & 177 & 148 & $0^{\mathrm{b}}$ & 148 & $-16 \%$ & 150 & 18 & 168 & $-5 \%$ \\
\hline CB. 3 & 302.7 & 986.5 & 37.3 & 281 & 218 & $0^{\mathrm{b}}$ & 218 & $-22 \%$ & 219 & 13 & 232 & $-17 \%$ \\
\hline
\end{tabular}

Footnotes: ${ }^{a}$ error based on measured value of Cocker et al. (2001). ${ }^{b}$ by definition

Table 3. Total mass concentration $T_{i}$ values for the hypothetical SOA+POA cases.

\begin{tabular}{|c|c|c|c|c|}
\hline \multicolumn{5}{|c|}{ SOA compounds } \\
\hline Rxn. & Parent & Oxidant & Compound & $T_{i}\left(\mu \mathrm{g} \mathrm{m}^{-3}\right)$ \\
\hline \multirow{2}{*}{1} & \multirow{2}{*}{$\alpha$-pinene } & \multirow{2}{*}{$\mathrm{OH}$} & S1 & 0.104 \\
\hline & & & S2 & 0.896 \\
\hline \multirow{2}{*}{2} & \multirow{2}{*}{$\alpha$-pinene } & \multirow[b]{2}{*}{$\mathrm{O}_{3}$} & $\mathrm{~S} 3$ & 0.551 \\
\hline & & & S4 & 0.449 \\
\hline \multirow{2}{*}{3} & \multirow{2}{*}{$\beta$-pinene } & \multirow{2}{*}{$\mathrm{OH}$} & S5 & 0.380 \\
\hline & & & S6 & 0.120 \\
\hline \multirow{2}{*}{4} & \multirow{2}{*}{$\beta$-pinene } & \multirow{2}{*}{$\mathrm{O}_{3}$} & S7 & 0.025 \\
\hline & & & S8 & 0.475 \\
\hline 5 & $\beta$-pinene & $\mathrm{NO}_{3}$ & S9 & 0.500 \\
\hline \multirow{2}{*}{6} & \multirow{2}{*}{ isoprene } & \multirow{2}{*}{$\mathrm{OH}$} & S10 & 0.111 \\
\hline & & & S11 & 0.014 \\
\hline \multirow{2}{*}{7} & \multirow{2}{*}{ limonene } & \multirow{2}{*}{$\mathrm{OH}$} & $\mathrm{S} 12$ & 0.397 \\
\hline & & & S13 & 0.603 \\
\hline \multirow{2}{*}{8} & \multirow{2}{*}{ ocimene } & \multirow{2}{*}{$\mathrm{OH}$} & S14 & 0.029 \\
\hline & & & S15 & 0.096 \\
\hline \multirow{2}{*}{9} & \multirow{2}{*}{ terpinene } & \multirow{2}{*}{$\mathrm{OH}$} & S16 & 0.025 \\
\hline & & & S17 & 0.100 \\
\hline \multirow{2}{*}{10} & \multirow{2}{*}{ toluene } & \multirow{2}{*}{$\mathrm{OH}$} & S18 & 0.849 \\
\hline & & & S19 & 1.650 \\
\hline \multirow{2}{*}{11} & \multirow{2}{*}{ xylene } & \multirow{2}{*}{$\mathrm{OH}$} & S20 & 0.324 \\
\hline & & & $\mathrm{S} 21$ & 1.430 \\
\hline 12 & humulene & $\mathrm{OH}$ & $\mathrm{S} 22$ & 0.125 \\
\hline \multirow{2}{*}{13} & \multirow{2}{*}{ 2-ring PAH } & $\mathrm{OH}$ & $\mathrm{S} 23$ & 0.125 \\
\hline & & ОП & $\mathrm{S} 24$ & 0.125 \\
\hline 14 & $\mathrm{C}_{16} n$-alkane & $\mathrm{OH}$ & $\mathrm{S} 25$ & 0.500 \\
\hline
\end{tabular}

required to compute the $\zeta_{i}$ values for 41 components in the mixture was obtained 100000 different times and then averaged, the large number allowing an averaging of the fluctuations in the CPU operation due to temporal variations in the system resource availability.
Table 3. Continued.

\begin{tabular}{lcc}
\hline \multicolumn{1}{c}{ POA compounds } & & $T_{i}\left(\mu \mathrm{g} \mathrm{m}^{-3}\right)$ \\
\hline 2,6-naphthalene diacid & P1 & 0.083 \\
benzo-ghi-perylene & P2 & 0.083 \\
butanedioic acid & P3 & 0.083 \\
17 $(\alpha) \mathrm{H}-21(\beta) \mathrm{H}$-hopane & P4 & 0.083 \\
$n$-nonacosane & P5 & 0.083 \\
octadecanoic acid & P6 & 0.083 \\
phthalic acid & P7 & 0.083 \\
UCM2 & P8 & 3.000 \\
monoglyceride & P9 & 0.083 \\
triglyceride & P10 & 0.083 \\
levoglucosan & P11 & 0.083 \\
UCM1 & P12 & 3.000 \\
UCM3 & P13 & 3.000 \\
hexadecanoic acid & P14 & 0.083 \\
glycerol & P15 & 0.083 \\
\hline
\end{tabular}

\subsubsection{Performance evaluation (PE) case for $\zeta_{i}$ prediction}

A performance evaluation (PE) aerosol case at $T=298 \mathrm{~K}$ for consideration of CP-Wilson.1 and UNIFAC in PM calculations with the $(N \cdot 2 \mathrm{p})^{\zeta_{p} \overline{\mathrm{MW}}, \theta}$ approach was selected to involve all 40 final surrogate compounds in Table 1 (and Fig. 1) each at $T_{i}=0.3 \mu \mathrm{g} \mathrm{m}^{-3}$, plus water at $\mathrm{RH}=50 \%$.

\subsubsection{Chamber based (CB) cases with $\mathrm{RH}=41$ to $58 \%$, $\Delta \mathrm{HC}=386$ to $986 \mu \mathrm{g} \mathrm{m}^{-3}$}

Cases CB. 1 to CB.3 involve $\alpha$-pinene/O $\mathrm{O}_{3}$ at $\mathrm{RH}$ values in the range 41 to $58 \%$ (Table 2), and were studied experimentally in the chamber study of Cocker et al. (2001). With $\alpha$-pinene as the only parent HC, only two surrogate product compounds from Table 1 (and Fig. 1) were considered, namely S3 and S4. The goal here was to allow a comparison of observed chamber PM levels with predictions based on: a) the $(N \cdot 2 \mathrm{p})^{\zeta_{p} \overline{\mathrm{MW}}, \theta}$ approach using the structures in Fig. 1 with CP-Wilson. 1 for the $\zeta_{i}$ calculations; and b) the conventional $N \cdot 2$ p approach. 


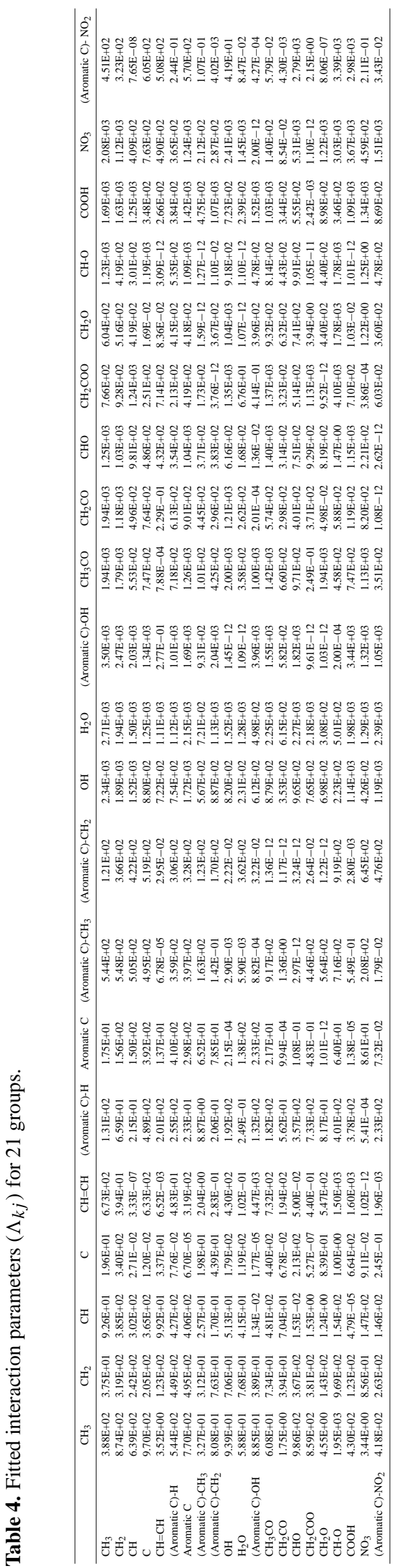




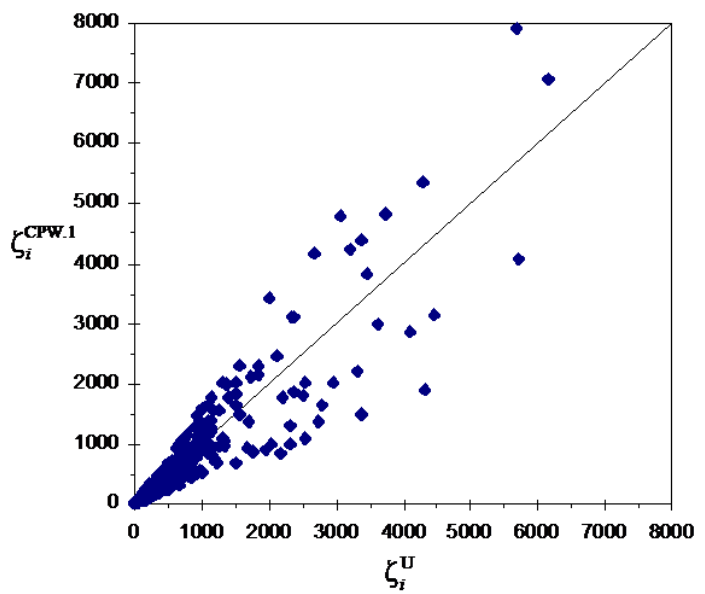

Fig. 2. $\zeta_{i}$ calculated by CP-Wilson. 1 vs. $\zeta_{i}$ calculated by UNIFAC for 13338 points used in the fitting of CP-Wilson.1 to UNIFAC.

\subsubsection{Hypothetical varying humidity cases}

To investigate $\mathrm{RH}$ effects at a lower $\Delta \mathrm{HC}$ than in the CB cases, an $\alpha$-pinene $/ \mathrm{O}_{3}$ series was considered assuming $\triangle \mathrm{HC}=30 \mu \mathrm{g} \mathrm{m}^{-3}$ with $\mathrm{RH}=20$ to $80 \%$ at $T=301 \mathrm{~K}$. Also, a hypothetical mixed SOA+POA series was developed with $T=301 \mathrm{~K}$ and two values of RH (5 and $80 \%$ ); all compounds were considered subject to G/P partitioning. The individual $T_{i}$ values for the SOA+POA series are given in Table 3 with $\sum_{\mathrm{SOA}} T_{i}=10 \mu \mathrm{g} \mathrm{m}^{-3}$ and $\sum_{\mathrm{POA}} T_{i}=10 \mu \mathrm{g} \mathrm{m}^{-3}$.

\section{Results}

\subsection{Fit quality for CP-Wilson.1 relative to UNIFAC}

Table 4 gives the best-fit values for the $441 \Lambda_{k j}$ parameters for CP-Wilson.1. The averaged unsigned percentage error for $\zeta_{i}$ relative to UNIFAC was calculated based on the 13338 pairs of predicted $\zeta_{i}^{\mathrm{CPW} .1}$ and $\zeta_{i}^{\mathrm{U}}$ values according to:

$\sigma_{\mathrm{FIT}}(\%)=100 \% \times \sum^{13338}\left|\frac{\zeta_{i}^{\mathrm{CPW} .1}-\zeta_{i}^{\mathrm{U}}}{\zeta_{i}^{\mathrm{U}}}\right| / 13338$

The overall fit quality was very good $\left(\sigma_{\mathrm{FIT}}=6 \%\right)$. Figure 2

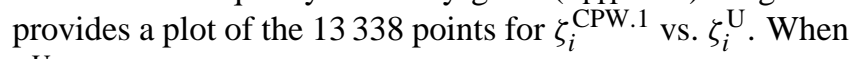
$\zeta_{i}^{\mathrm{U}}<1000$, where $>99 \%$ of the points are located, the values are in good agreement. (The good quality of the fit is masked to a considerable extent by the fact that many of the 13338 points are near the $1: 1$ line, and plot essentially on top of one another.) For $\zeta_{i}^{\mathrm{U}}>1000$, the agreement is still within a factor of $\sim 2$. Moreover, contributions to prediction errors for the mass totals given by Eqs. (17-20) are not likely to be caused simply by incorrectly estimating a large $\zeta_{i}$ value. Indeed, when there is one liquid phase, such an error can only be significant if the corresponding $x_{i}$ is also of a significant
Table 5. Comparison of relative computer processing time required for six $\zeta_{i}$ prediction methods.

\begin{tabular}{cccc}
\hline$\zeta_{i}$ method & $\begin{array}{c}\text { Method } \\
\text { type }\end{array}$ & $\begin{array}{c}\text { Number of groups } \\
\text { or compounds }\end{array}$ & $\begin{array}{c}\text { Relative computer } \\
\text { processing time }\end{array}$ \\
\hline CP-Wilson.1 & group & 21 & 0.1 \\
Wilson & compound & 41 & 0.6 \\
UNIQUAC & compound & 41 & 0.6 \\
TK-Wilson & compound & 41 & 0.7 \\
NRTL & compound & 41 & 0.8 \\
UNIFAC & compound & 21 & 1.0 \\
\hline
\end{tabular}

magnitude. However, in that case, large $x_{i}$ with corresponding large $\zeta_{i}$ would lead to a high Gibbs free energy so that the phase would very likely be unstable relative to phase separation, in which case the $i$-related prediction error for the mass total would become small because most of the $i$ would retreat into the new, second phase in which $\zeta_{i}$ would be relatively close to 1 and thus reliably estimated.

\subsection{CP-Wilson.1 vs. other methods for the computa- tional efficiency $(\mathrm{CE})$ case}

Table 5 compares the CPU requirements of CP-Wilson.1 with five other $\zeta_{i}$ methods for the CE case. CP-Wilson. 1 gave the best result. The economy of this method is achieved by the combination of its group contribution nature (21 groups for the CE case instead of 41 compounds), and its relatively small need for logarithm and double summation operations. While not implemented here, the computational efficiency of a CP-Wilson. 1 code can be assisted by utilizing a lookup table to evaluate the logarithm term in Eq. (12).

\subsection{CP-Wilson.1 vs. UNIFAC for performance evalua- tion (PE) case}

When CP-Wilson.1 is used in the $(N \cdot 2 \mathrm{p})^{\zeta_{p} \overline{\mathrm{MW}}, \theta}$ approach to predict $\zeta_{i}$ in the liquid PM formed in the PE case (all $T_{i}=0.3 \mu \mathrm{g} \mathrm{m}^{-3}$ for the organic components, and $\mathrm{RH}=50 \%$ ), two phases are revealed as being present in the PM at equilibrium; use of UNIFAC leads to the same result. For each phase $\theta$, relative to UNIFAC, the unsigned prediction difference $(\%)$ for $x_{i}^{\theta}$ is defined

$\delta_{x, i}^{\theta}=\frac{x_{i}^{\theta, \mathrm{CPW} .1}-x_{i}^{\theta, \mathrm{U}}}{x_{i}^{\theta, \mathrm{U}}} \times 100 \%$

where the superscripts on $x_{i}$ denote the phase and $\zeta_{i}$ method. For the $\alpha$ phase, a plot of $\delta_{x, i}^{\alpha}$ vs. $\log _{10} x_{i}^{\alpha, \mathrm{U}}$ is given in Fig. 3a for the 40 compounds and water. A corresponding plot for the $\beta$ phase is given in Fig. 3b. Consistent with the results in Fig. $2, \delta_{x, i}^{\alpha}$ is small when $x_{i}^{\alpha, \mathrm{U}}>0.01$, and the corresponding $\delta_{x, i}^{\beta}$ are small when $x_{i}^{\beta, \mathrm{U}}>0.01$. 

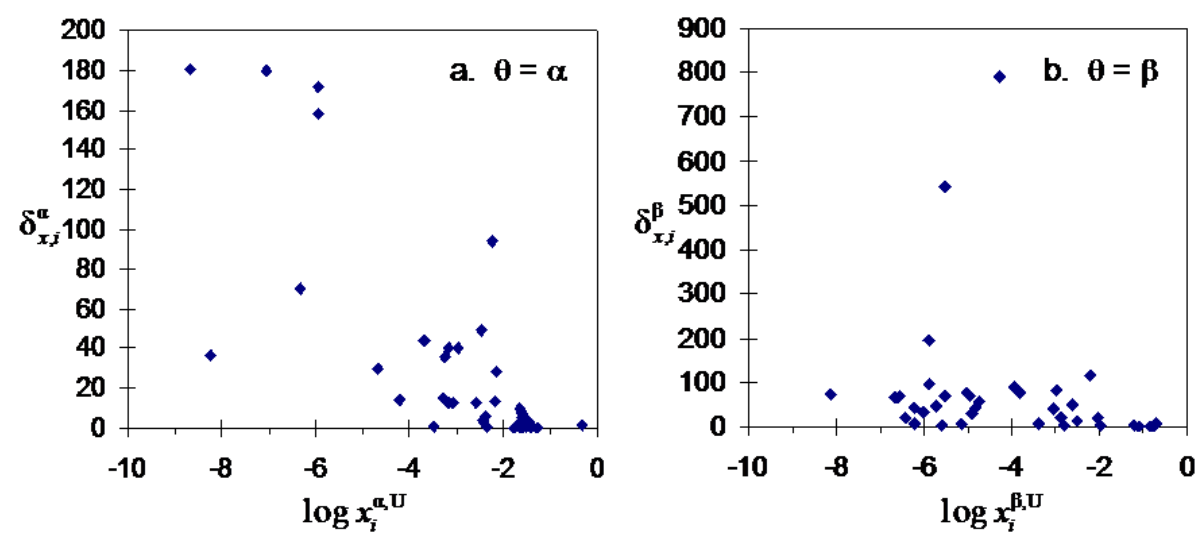

Fig. 3. Unsigned percentage difference between the values of $x_{i}^{\theta}$ as predicted using CP-Wilson.1 and UNIFAC plotted vs. log $x_{i}^{\theta, \mathrm{U}}$ (U=UNIFAC) for $\theta=\alpha$ and for $\theta=\beta$ in the performance evaluation (PE) case.
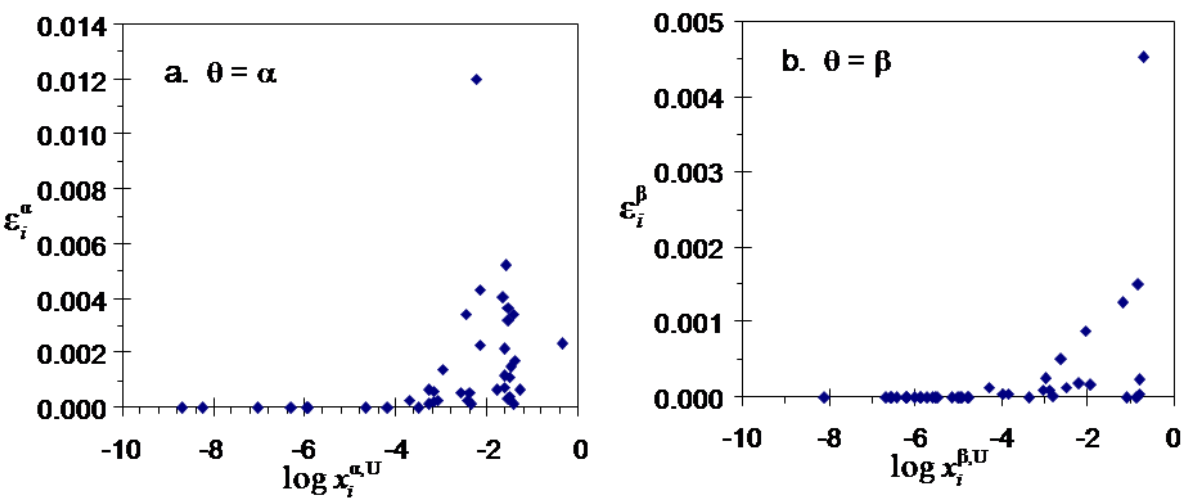

Fig. 4. Unsigned difference between the values of $F_{i}^{\theta}$ as predicted using CP-Wilson.1 and UNIFAC expressed as a percentage of $\left(M_{\mathrm{TPM}}\right)^{\mathrm{U}}$ vs. $\log x_{i}^{\theta, \mathrm{U}}$ (U=UNIFAC) for $\theta=\alpha$ and for $\theta=\beta$ in the performance evaluation (PE) case.

Table 6. Comparison of predictions for the performance evaluation (PE) case by the approach using the CP-Wilson.1 method and the UNIFAC method ( $T=298 \mathrm{~K}, \mathrm{RH}=50 \%)$.

\begin{tabular}{lcc}
\hline & \multicolumn{2}{c}{$\zeta_{i}$ Method } \\
Result & CP-Wilson.1 & UNIFAC \\
\hline Number of PM phases & 2 & 2 \\
$M_{\mathrm{O}}^{\alpha}, M_{\mathrm{O}}^{\beta}\left(\mu \mathrm{g} \mathrm{m}^{-3}\right)$ & $3.63,1.79$ & $3.62,1.79$ \\
$M_{\mathrm{O}}=M_{\mathrm{O}}^{\alpha}+M_{\mathrm{O}}^{\beta}\left(\mu \mathrm{g} \mathrm{m}^{-3}\right)$ & 5.42 & 5.41 \\
$M_{\mathrm{W}}^{\alpha}, M_{\mathrm{W}}^{\beta}\left(\mu \mathrm{g} \mathrm{m}^{-3}\right)$ & $0.29,0.001$ & $0.29,0.0005$ \\
$M_{\mathrm{W}}=M_{\mathrm{w}}^{\alpha}+M_{\mathrm{w}}^{\beta}\left(\mu \mathrm{g} \mathrm{m}^{-3}\right)$ & 0.29 & 0.29 \\
$M_{\mathrm{TPM}}^{\alpha}\left(\mu \mathrm{g} \mathrm{m}^{-3}\right)$ & 3.92 & 3.92 \\
$M_{\mathrm{TPM}}^{\beta}\left(\mu \mathrm{g} \mathrm{m}^{-3}\right)$ & 1.79 & 1.79 \\
$M_{\mathrm{TPM}}\left(\mu \mathrm{g} \mathrm{m}^{-3}\right)$ & 5.71 & 5.71 \\
\hline
\end{tabular}

Table 6 provides observed and predicted results for $M_{\mathrm{O}}$, $M_{\mathrm{W}}$, and $M_{\mathrm{TPM}}$ for the PE case. While UNIFAC does not provide perfect estimates of $\zeta_{i}$, the similarity of the predicted results as obtained using CP-Wilson.1 vs. UNIFAC supports the view discussed above that errors associated with large $\zeta_{i}^{\theta}$ are not likely to have significant effects on the quality of predictions for gross parameters such as $M_{\mathrm{o}}, M_{\mathrm{W}}$, and $M_{\mathrm{TPM}}$ $\left(=M_{\mathrm{o}}+M_{\mathrm{W}}\right)$.

The extent to which an error in a given $x_{i}^{\theta}$ value translates into an error in $M_{\mathrm{TPM}}$ depends on the magnitude of $x_{i}^{\theta}$ and on the size of the $\theta$ phase. For UNIFAC-based predictions, the fraction (\%) of the total PM phase identified with $i$ in the $\theta$-phase equals $F_{i}^{\theta, \mathrm{U}} \times 100 \% / M_{\mathrm{TPM}}^{\mathrm{U}}$. While UNIFAC is certainly also subject to increasing prediction error as any given $\zeta_{i}$ increases, it is again perhaps the best available benchmark for evaluating the results obtained using CP-Wilson.1. Thus, as an means to evaluate the implications of incorrectly predicting $F_{i}^{\theta}$ we define

$\varepsilon_{i}^{\theta}=\left|\left(F_{i}^{\theta, \mathrm{CPW} .1}-F_{i}^{\theta, \mathrm{U}}\right) /\left(M_{\mathrm{TPM}}\right)^{\mathrm{U}}\right| \times 100 \%$

If $\varepsilon_{i}^{\theta}$ is small, either $F_{i}^{\theta, \mathrm{CPW} .1} \approx F_{i}^{\theta, \mathrm{U}}$, or both are small relative to $M_{\mathrm{TPM}}$. Figure $4 \mathrm{a}$ and $\mathrm{b}$ provides plots of $\varepsilon_{i}^{\theta}$ vs. $\log _{10} x_{i}^{\theta, \mathrm{U}}$ for the PE case. For both $\theta=\alpha$, and $\theta=\beta$, 
Table 7. Results for the hypothetical SOA+POA cases at $300 \mathrm{~K}$ as predicted using the $N \cdot 2 \mathrm{p}$ approach and using the $(N \cdot 2 \mathrm{p})^{\zeta \overline{\mathrm{MW}}, \theta}$ approach with the CP-Wilson. 1 method for prediction of $\zeta_{i}$ values (see Table 3 for all $T_{i}$ values).

\begin{tabular}{c|cccc|ccccc}
\hline & \multicolumn{4}{|c|}{$N \cdot 2 \mathrm{p}$ prediction } & \multicolumn{5}{c}{$(N \cdot 2 \mathrm{p})^{\zeta \overline{\mathrm{MW}}, \theta}$ prediction } \\
\hline $\begin{array}{c}\mathrm{RH} \\
(\%)\end{array}$ & $\begin{array}{c}M_{\mathrm{O}} \\
\left(\mu \mathrm{g} \mathrm{m}^{-3}\right)\end{array}$ & $\begin{array}{c}M_{\mathrm{W}} \\
\left(\mu \mathrm{g} \mathrm{m}^{-3}\right)\end{array}$ & $\begin{array}{c}M_{\mathrm{TPM}} \\
\left(\mu \mathrm{g} \mathrm{m}^{-3}\right)\end{array}$ & PM phases & $\begin{array}{c}M_{\mathrm{O}} \\
\left(\mu \mathrm{g} \mathrm{m}^{-3}\right)\end{array}$ & $\begin{array}{c}M_{\mathrm{W}} \\
\left(\mu \mathrm{g} \mathrm{m}^{-3}\right)\end{array}$ & $\begin{array}{c}M_{\mathrm{TPM}} \\
\left(\mu \mathrm{g} \mathrm{m}^{-3}\right)\end{array}$ & $\begin{array}{c}\text { PM phases } \\
\text { phase mass distribution } \\
M_{\mathrm{TPM}}^{\alpha} / M_{\mathrm{TPM}}^{\beta}\end{array}$ \\
\hline 5 & 9.23 & $0^{\mathrm{a}}$ & 9.23 & $1^{\mathrm{a}}$ & 6.48 & 0.001 & 6.48 & 2 & $0.19 / 6.29$ \\
80 & 9.23 & $0^{\mathrm{a}}$ & 9.23 & $1^{\mathrm{a}}$ & 10.00 & 1.28 & 11.28 & 2 & $5.02 / 6.26$ \\
\hline
\end{tabular}

a by definition

$\varepsilon_{i}^{\theta}$ becomes small as $\log _{10} x_{i}^{\theta, \mathrm{U}}$ increases. This is a consequence of the fact that when phase separation occurs, if $\zeta_{i}^{\alpha}$ is large (and thus subject to some error regardless of the prediction method used), then $\zeta_{i}^{\beta}$ is relatively close to 1 (and vice versa), the overall result being a thermodynamically driven minimization of the mass amount of $i$ in the less-hospitable phase where $\zeta_{i}$ is more difficult to predict (see discussion above). This type of hyperbolic behavior in $\log _{10} \zeta_{i}^{\alpha}$ vs. $\log _{10} \zeta_{i}^{\beta}$ is clearly evident in Fig. 5. For compounds that fall in the middle of the hydrophobicity $\leftrightarrow$ hydrophilicity scale, both $\zeta_{i}^{\alpha}$ and $\zeta_{i}^{\beta}$ are neither near 1 nor very large. E.g., for P6, both $\zeta_{i}^{\alpha}$ and $\zeta_{i}^{\beta}$ are of order 10 because P6 is not particularly "comfortable" in either phase.

\subsection{Predictions for chamber based (CB) and hypotheti- cal cases}

\subsubsection{CB cases for $\alpha$-Pinene/ $\mathrm{O}_{3}$ with $\mathrm{RH}=41$ to $58 \%$}

Table 2 provides $M_{\text {TPM }}$ values measured by Cocker et al. (2001) along with the predicted values of $M_{\mathrm{o}}, M_{\mathrm{w}}$, and $M_{\text {TPM }}$ using the $(N \cdot 2 \mathrm{p})^{\zeta_{p} \overline{\mathrm{MW}}, \theta}$ approach with CP-Wilson.1 and the assumed structures for products S3 and S4. For all three CB cases, use of CP-Wilson.1 indicates a single PM phase. (In this and all other respects for these cases, UNIFAC gives similar results.) At these moderate $\mathrm{RH}$ values, water uptake is low and $\zeta_{\mathrm{S} 3}$ and $\zeta_{\mathrm{S} 4}$ values are $\sim 1.3$, i.e., relatively close to unity. The prediction errors for $M_{\mathrm{TPM}}$ as compared to the chamber experiments ranged from -17 to $3 \%$ for the three cases. Table 2 also provides $M_{\mathrm{o}}$ as predicted using the $n \cdot 2 \mathrm{p}$ approach for which, as has been noted, all $\zeta_{i} \equiv 1, M_{\mathrm{O}} \equiv M_{\mathrm{TPM}}$, and $\overline{\mathrm{MW}} \equiv$ constant. The prediction errors for the $N \cdot 2 \mathrm{p}$ approach ranged from -22 to $-5 \%$. The two approaches give nearly the same results because the assumed structures for S3 and S4 have similar polarities and $\mathrm{MW}_{i}$ values, and the water uptake is relatively low. Also, the good agreement under these conditions between the experimental results of Cocker et al. (2001) and the predictions based on the $N \cdot 2$ p approach indicate good consistency between the Cocker et al. (2001) yield results and the $K_{\mathrm{p}, i}$ and $\alpha_{i}$ values given in Table 1 for $\alpha$-pinene/ $\mathrm{O}_{3}$.

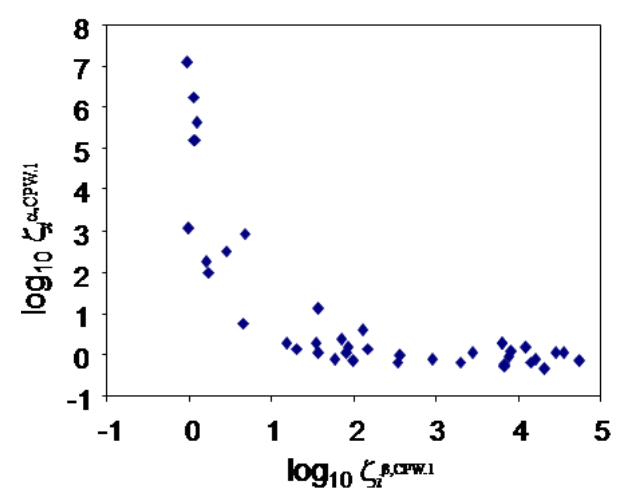

Fig. 5. Hyperbolic relationship between $\log _{10} \zeta_{i}^{\alpha}$ vs. $\log _{10} \zeta_{i}^{\beta}$ as calculated in the performance evaluation (PE) case by the CP-Wilson.1 method.

\subsubsection{Hypothetical $\alpha$-pinene $/ \mathrm{O}_{3}$ series}

Results based on the $N \cdot 2 \mathrm{p}$ and $(N \cdot 2 \mathrm{p})^{\zeta_{p} \overline{\mathrm{MW}}, \theta}$ approaches for the $\alpha$-pinene $/ \mathrm{O}_{3}$ series are given in Fig. 6 . As with the CB cases, use of CP-Wilson. 1 in the $(N \cdot 2 \mathrm{p})^{\zeta_{p} \overline{\mathrm{MW}}, \theta}$ approach indicates a single PM phase for the entire $\mathrm{RH}$ range (20 to $80 \%$ ). However, the difference in the $M_{\mathrm{o}}$ predictions obtained using the $N \cdot 2 \mathrm{p}$ approach with no water uptake and $(N \cdot 2 \mathrm{p})^{\zeta_{p} \overline{\mathrm{MW}}, \theta}$ with water uptake is much greater in the Fig. 6 series than in the CB cases: $M_{\mathrm{o}}$ by the $(N \cdot 2 \mathrm{p})^{\zeta_{p} \overline{\mathrm{MW}}, \theta}$ approach in Fig. 6 increases by more than $3 \times$ as RH increases from 20 to $80 \%$. The increase in $M_{\mathrm{o}}$ by the $(N \cdot 2 \mathrm{p})^{\zeta p} \overline{\mathrm{MW}}, \theta$ approach is driven mostly by the decreasing $\overline{\mathrm{MW}}$ brought about by water absorption $\left(\overline{\mathrm{MW}}=151 \mathrm{~g} \mathrm{~mol}^{-1}\right.$ at $\mathrm{RH}=20 \%$, and $64 \mathrm{~g} \mathrm{~mol}^{-1}$ at $\mathrm{RH}=80 \%$ ), but is also compounded somewhat by the behavior of $\zeta_{\mathrm{S} 3}$, which changes from 1.6 at $\mathrm{RH}=20 \%$, to 1.1 at $\mathrm{RH}=80 \%$ ( $\zeta \mathrm{S} 4$ remains essentially unchanged at 1.3).

For mono-phasic PM, based on Liang and Pankow (1996), the fraction of $i$ in the particle phase is given by

$f_{\mathrm{p}, i}=\frac{K_{\mathrm{p}, i} M_{\mathrm{TPM}}}{1+K_{\mathrm{p}, i} M_{\mathrm{TPM}}}$ 


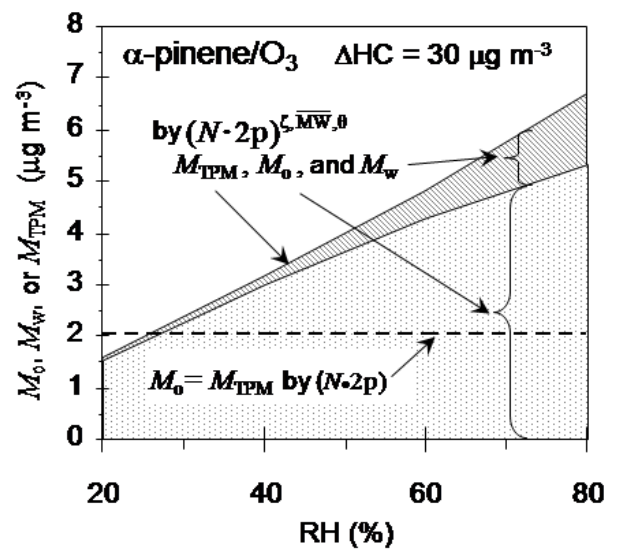

Fig. 6. $M_{\mathrm{O}}, M_{\mathrm{W}}$, and $M_{\mathrm{TPM}}$ by the $(N .2 \mathrm{p})^{\zeta, \overline{\mathrm{MW}}, \theta}$ approach using the CP-Wilson.1 method for the activity coefficients for the $\alpha$-pinene $/ \mathrm{O}_{3}$ products, with $\Delta \mathrm{HC}=30 \mu \mathrm{g} \mathrm{m}^{-3}$; for comparison, $M_{\mathrm{O}}=M_{\mathrm{TPM}}$ by the $N \cdot 2 \mathrm{p}$ approach is also given.

(Donahue et al. (2006) denote $f_{\mathrm{p}, i}$ as $\xi_{i}$.) When $K_{\mathrm{p}, i} M_{\mathrm{TPM}}$ is large relative to $1, f_{\mathrm{p}, i} \approx 1$, and the contribution that $i$ makes to $M_{\mathrm{TPM}}$ is relatively insensitive to changes in $K_{\mathrm{p}, i}$ that may be caused by changes in RH, $T$, and other factors. However, as $f_{\mathrm{p}, i}$ decreases away from 1 , that sensitivity increases. Thus, as compared to the CB cases and as compared to the monoterpene cases considered by Seinfeld et al. (2001), $M_{\text {TPM }}$ in the series in Fig. 6 is much lower, and $M_{\mathrm{o}}$ is thus much more sensitive to RH. Pankow and Chang (2008) provide additional perspective on why the sensitivity of $M_{\mathrm{o}}$ and $M_{\text {TPM }}$ predictions will tend to increase as the levels of condensable compounds decrease.

\subsubsection{SOA+POA system}

Table 7 provides predicted results assuming the Table 3 levels of SOA+POA compounds at $T=301 \mathrm{~K}$ for $\mathrm{RH}=5 \%$ and $80 \%$. In each of these two cases, the $(N \cdot 2 \mathrm{p})^{\zeta p \overline{\mathrm{MW}}, \theta}$ approach using CP-Wilson.1 predicts two liquid phases in the PM, with the $\alpha$ phase containing mostly SOA compounds and water, and the $\beta$ phase containing mostly POA compounds and little water. At $\mathrm{RH}=5 \%$, for the major components in each PM phase, $\zeta_{i}^{\theta} \approx 1$. Because of the considerable mutual exclusion of the SOA and POA compounds, the effective size of the $\mathrm{PM}$ compartment at $\mathrm{RH}=5 \%$ is significantly lower than is predicted using the $N \cdot 2 \mathrm{p}$ approach: $M_{\mathrm{W}}$ and $M_{\mathrm{o}}$ based on the $(N \cdot 2 \mathrm{p})^{\zeta p \mathrm{MW}, \theta}$ approach are 0.001 and $6.5 \mu \mathrm{g} \mathrm{m}^{-3}$. By the $N \cdot 2 \mathrm{p}$ approach, the corresponding values are 0 and $9.2 \mu \mathrm{g} \mathrm{m}^{-3}$. For the $\mathrm{RH}=80 \%$ case, significant mutual exclusion of the SOA and POA compounds still operates. However, significant water uptake into the $\alpha$ phase is now predicted. This tends to increase the $f_{\mathrm{p}, i}$ values of the more polar compounds because $M_{\mathrm{TPM}}^{\alpha}$ is relatively larger and $\overline{\mathrm{MW}}^{\alpha}$ relatively smaller than at $\mathrm{RH}=5 \%$. Moreover, because of the resulting increased $M_{\mathrm{w}}^{\alpha}$ value, several of the rather polar com- pounds take on significantly reduced $\zeta_{i}^{\alpha}$ values (for $\mathrm{S} 8,10$, $12,14,20$ and P11, the range for $\zeta_{i}^{\alpha}$ is 0.2 to 0.6). The overall result is that at $\mathrm{RH}=80 \%, M_{\mathrm{w}}$ and $M_{\mathrm{o}}$ based on the $(N \cdot 2 \mathrm{p})^{\zeta_{p} \overline{\mathrm{MW}}, \theta}$ approach are 1.3 and $10.0 \mu \mathrm{g} \mathrm{m}^{-3}$ vs. 0 and $9.2 \mu \mathrm{g} \mathrm{m}^{-3}$ by the $N \cdot 2 \mathrm{p}$ approach.

\section{Conclusions}

The approximations for the particulate matter (PM) phase incorporated in the multiple lumped "two-product" $(N \cdot 2 \mathrm{p})$ approach for SOA PM (i.e., all $\zeta_{i}=1, \overline{\mathrm{MW}}$ is constant, and no water uptake occurs at ambient RH levels) will become increasingly problematic as $M_{\mathrm{o}}$ levels decrease. Also, the approximation of a single-absorbing phase as utilized in the $N \cdot 2 \mathrm{p}$ approach can become invalid when RH levels are high, and/or when significant levels of both SOA and POA compounds are present. The structures proposed here for partitioning SOA and POA compounds will allow first stage usage of the $(N \cdot 2 \mathrm{p})^{\zeta_{p} \overline{\mathrm{MW}}, \theta}$ approach for ambient PM modeling; the CP-Wilson.1 $\zeta_{i}$-prediction method developed here allows consideration of computationally intensive space-time domains.

Acknowledgements. This work was supported by National Science Foundation Grant ATM-0513492, by the Electric Power Research Institute, by the Cooley Family Fund for Critical Research of the Oregon Community Foundation, and by S. T. Huff. The assistance of R. J. Griffin in developing structures for the surrogate SOA compounds is deeply appreciated.

Edited by: A. Nenes

\section{References}

Abram, D. S. and Prausnitz, J. M.: Statistical thermodynamics of liquid mixtures: a new expres- sion for the excess Gibbs energy of partly or completely miscible systems, AIChE Journal, 21, 116-128, 1975.

Barsanti, K. C. and Pankow, J. F.: Thermodynamics of the formation of atmospheric organic particulate matter by accretion reactions, Part 1: aldehydes and ketones, Atmos. Environ., 38, 43714382, 2004.

Barsanti, K. C. and Pankow, J. F.: Thermodynamics of the formation of atmospheric organic particulate matter by accretion reactions-2. Dialdehydes, methylglyoxal, and diketones, Atmos. Environ., 39, 6597-6607, 2005.

Barsanti, K. C. and Pankow, J. F.: Thermodynamics of the formation of atmospheric organic particulate matter by accretion reactions-Part 3: Carboxylic and dicarboxylic acids, Atmos. Environ., 40, 6676-6686, 2006.

Bates, T. S., Anderson, T. L., Baynard, T., Bond, T., Boucher, O., Carmichael, G., Clarke, A., Erlick, C., Guo, H., Horowitz, L., Howell, S., Kulkarni, S., Maring, H., McComiskey, A., Middlebrook, A., Noone, K., O’Dowd, C. D., Ogren, J., Penner, J., Quinn, P. K., Ravishankara, A. R., Savoie, D. L., Schwartz, S. E., Shinozuka, Y., Tang, Y., Weber, R. J., and Wu, Y.: Aerosol direct 
radiative effects over the northwest Atlantic, northwest Pacific, and North Indian Oceans: estimates based on in-situ chemical and optical measurements and chemical transport modeling, Atmos. Chem. Phys., 6, 1657-1732, 2006,

http://www.atmos-chem-phys.net/6/1657/2006/.

Bowman, F. M. and Karamalegos, A. M.: Estimated effects of composition on secondary organic aerosol mass concentrations, Environ. Sci. Technol., 36, 2701-2707, 2002.

Bowman, F. M. and Melton, J. A.: Effect of activity coefficient models on predictions of secondary organic aerosol partitioning, J. Aerosol Sci., 35, 1415-1438, 2004.

Chang, E. I. and Pankow, J. F.: Prediction of activity coefficients in liquid aerosol particles containing organic compounds, dissolved inorganic salts, and water-Part 2: Consideration of phase separation effects by an X-UNFIAC model, Atmos. Environ., 40, 6422-6436, 2006.

Cocker III, D. R., Cleggb, S. L., Flagana, R. C., and Seinfelda, J. H.: The effect of water on gas-particle partitioning of secondary organic aerosol, Part I: $\alpha$-pinene/ozone system, Atmos. Environ., 35, 6049-6072, 2001.

Donahue, N. M., Robinson, A. L., Stanier, C. O., and Pandis, S. N.: Coupled partitioning, dilution, and chemical aging of semivolatile organics, Environ. Sci. Technol., 40, 2635-2643, 2006.

Erdakos, G. B. and Pankow, J. F.: Gas/particle partitioning of neutral and ionizing compounds to single- and multi-phase aerosol particles. 2. Phase separation in liquid particulate matter containing both polar and low-polarity organic compounds, Atmos. Environ., 38, 1005-1013, 2004.

Flory, P. J.: Principles of Polymer Chemistry, Cornell University Press, Ithaca, New York, 1953.

Fraser, M. P., Yue, Z. W., Tropp, R. J., Kohl, S. D., and Chow, J. C.: Molecular composition of organic fine particulate matter in Houston, TX, Atmos. Environ., 36, 5751-5758, 2002.

Fredenslund, A., Jones, R. L., and Prausnitz, J. M.: Groupcontribution estimation of activity coefficients in nonideal mixtures, AIChE Journal, 21, 1086-1099, 1975.

Griffin, R. J., Cocker III, D. R., Flagan, R. C., and Seinfeld, J. H.: Organic aerosol formation from the oxidation of biogenic hydrocarbons, J. Geophys. Res., 104, 3555-3568, 1999.

Griffin, R. J., Dabdub, D., Kleeman, M. J., Fraser, M. P., Cass, G. R., and Seinfeld, J. H.: Secondary organic aerosol. 3. Urban/regional scale model of size- and composition-resolved aerosols, J. Geophys. Res., 107, AAC5.1-AAC5.14, 2002a.

Griffin, R. J., Dabdub, D., and Seinfeld, J. H.: Secondary organic aerosol. 1. Atmospheric chemical mechanism for production of molecular constituents, J. Geophys. Res., 107, AAC3.1AAC 3.26, 2002b.

Griffin, R. J., Nguyen, K., Dabdub, D., and Seinfeld, J. H.: A coupled hydrophobic-hydrophilic model for predicting secondary organic aerosol formation, J. Atmos. Chem., 44, 171-190, 2003.

Henze, D. K. and Seinfeld, J. H.: Global secondary organic aerosol from isoprene oxidation, Geophys. Res. Lett., 33, L09812, doi:10.1029/2006GL025976, 2007.

Hoffman, T., Odum, J. R., Bowman, F., Collins, D., Klockow, D., Flagan, R. C., and Seinfeld, J. H.: Formation of organic aerosols from the oxidation of biogenic hydrocarbons, J. Atmos. Chem., 26, 189-222, 1997.

Kalberer, M., Paulsen, D., Sax, M., Dommen, J., Prevot, A. S. H.,
Fisseha, R., Weingartner, E., Frankevich, V., Zenobi, R., and Baltensperger, U.: Identification of polymers as major components of atmospheric organic aerosols, Science, 303, 1659-1662, 2004.

Kanakidou, M., Tsigaridis, K., Dentener, F. J., and Crutzen, P. J.: Human-activity-enhanced formation of organic aerosols by biogenic hydrocarbon oxidation, J. Geophys. Res., 105, 9243-9254, 2000.

Liang, C. and Pankow, J. F.: Gas/particle partitioning of organic compounds to environmental tobacco smoke: partition coefficient measurements by desorption and comparison to urban particulate material, Environ. Sci. Technol., 30, 2800-2805, 1996.

Levenberg, K.: A method for the solution of certain problems in least Squares, Q. Appl. Math., 2, 164-168, 1944.

Mazurek, M., Masonjones, M. C., Masonjones, H. D., Salmon, L. G., Cass, G. R., Hallock, K. A., and Leach, M.: Visibilityreducing organic aerosols in the vicinity of Grand Canyon National Park: Properties observed by high resolution gas chromatography, J. Geophys. Res., 102, 3779-3794, 1997.

Nolte, C. G., Schauer, J. J., Cass, G. R., and Simoneit, B. R. T.: Highly polar organic compounds present in meat smoke, Environ. Sci. Technol., 33, 3313-3316, 1999.

Odum, J. R., Hoffmann, T., Bowman, F., Collins, D., Flagan, R. C., and Seinfeld, J. H.: Gas/particle partitioning and secondary organic aerosol yields, Environ. Sci. Technol., 30, 2580-2585, 1996.

Odum, J. R., Jungkamp, T. P. W., Griffin, R. J., Forstner, H. J. L., Flagan, R. C., and Seinfeld, J. H.: Aromatics, reformulated gasoline, and atmospheric organic aerosol formation, Environ. Sci. Technol., 31, 1890-1897, 1997.

Pankow, J. F.: An absorption model of gas/particle partitioning of organic compounds in the atmosphere, Atmos. Environ., 28, 185-188, 1994a.

Pankow, J. F.: An absorption model of the gas/aerosol partitioning involved in the formation of secondary organic aerosol, Atmos. Environ., 28, 189-193, 1994b.

Pankow, J. F. and Asher, W. E.: SIMPOL.1: a simple group contribution method for predicting vapor pressures and enthalpies of vaporization of multifunctional organic compounds, Atmos. Chem. Phys., 8, 2773-2796, 2008, http://www.atmos-chem-phys.net/8/2773/2008/.

Pankow, J. F. and Chang, E. I.: Variation in the sensitivity of predicted levels of atmospheric organic particulate matter (OPM), Environ. Sci. Technol., 42, 7321-7329, 2008.

Pankow J. F. and Barsanti, K. C.: The carbon number-polarity grid: A means to manage the complexity of the mix of organic compounds when modeling atmospheric organic particulate matter, Atmos. Environ., 43, 2829-2835, 2009.

Pope, C. A.: Epidemiology of fine particulate air pollution and human health: biologic mechanisms and who's at risk, Environ. Health Perspect, 108, 713-723, 2000.

Pun, B. K., Zhang, Y., Vijayaraghavan, K., Wu, S., Seigneur, C., and Seinfeld, J. H.: Development and initial application of the model for aerosol dynamics, reaction, ionization, and dissolution (MADRID). Regional Haze and Global Radiation Balance: Aerosol Measurements and Models-Closure, Reconciliation and Evaluation, Proceedings of a Specialty Conference, Bend, OR, United States, 104-113, 2-5 October 2001.

Pun, B. K., Wu, S. Y., Seigneur, C., Seinfeld, J. H., Griffin, R. J., and Pandis S. N.: Uncertainties in modeling sec- 
ondary organic aerosols: three-dimensional modeling studies in Nashville/western Tennessee, Environ. Sci. Technol., 37, 36473661, 2003.

Renon, H. and Prausnitz, J. M.: Local compositions in thermodynamic excess functions for liquid mixtures, AIChE Journal, 14, 135-144, 1968.

Seinfeld, J. H., Erdakos, G. B., Asher, W. E., and Pankow, J. F.: Modeling the formation of secondary organic aerosol (SOA). 2 . The predicted effects of relative humidity on aerosol formation in the $\alpha$-pinene-, $\beta$-pinene-, sabinene-, $\Delta 3$-carene-, and cyclohexene-ozone systems, Environ. Sci. Technol., 35, 18061817, 2001.

Simoneit, B. R. T., Rogge, W. F., Lang, Q., and Jaffe, R.: Molecular characterization of smoke from campfire burning of pine wood (Pinus elliottii), Chemosphere: Global Change Sci., 2, 107-122, 2000.

Sheehan, P. E. and Bowman, F. M.: Estimated effects of temperature on secondary organic aerosol concentrations, Environ. Sci. Technol., 35, 2129-2135, 2001.
Surratt, J. D., Murphy, S. M., Kroll, J. H., Ng, N. L., Hildebrandt, L., Sorooshian, A., Szmigielski, R., Vermeylen, R., Maenhaut, W., Claeys, M., Flagan, R. C., and Seinfeld, J. H.: Chemical composition of secondary organic aerosol formed from the photooxidation of isoprene, J. Phys. Chem. A, 110, 9665-9690, 2006.

Tsigaridis, K. and Kanakidou, M.: Global modelling of secondary organic aerosol in the troposphere: a sensitivity analysis, Atmos. Chem. Phys., 3, 1849-1869, 2003, http://www.atmos-chem-phys.net/3/1849/2003/.

Tsuboka, T. and Katayama, T.: Modified Wilson equation for vaporliquid and liquid-liquid equilibria, J. Chem. Eng. Japan, 8, 181187, 1975.

Wilson, G. M.: Vapor-Liquid Equilibrium. XI. A new expression for the excess free energy of mixing, J. Am. Chem. Soc., 86, 127-130, 1964.

Zhao, Y., Hu, M., Slanina, S., and Zhang, Y.: Chemical compositions of fine particle organic matter emitted from Chinese cooking, Environ. Sci. Technol., 41, 99-105, 2007. 